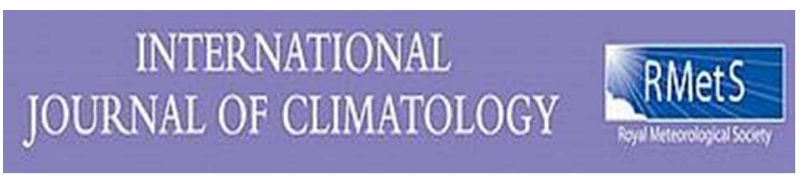

\title{
North Atlantic circulation indices: links with summer and winter UK temperature and precipitation and implications for seasonal forecasting.
}

\begin{tabular}{|r|l|}
\hline Journal: & International Journal of Climatology \\
\hline Manuscript ID & JOC-17-0557.R2 \\
\hline Wiley - Manuscript type: & Research Article \\
\hline Complete List of Authors: & $\begin{array}{l}\text { Hall, Richard; University of Lincoln, School of Geography and Lincoln } \\
\text { Centre for Water and Planetary Health } \\
\text { Hanna, Edward; University of Lincoln, School of Geography and Lincoln } \\
\text { Centre for Water and Planetary Health }\end{array}$ \\
\hline Keywords: & $\begin{array}{l}\text { jet stream, North Atlantic Oscillation, precipitation, seasonal forecasting, } \\
\text { temperature, correlation, EOF, UK regional climate }\end{array}$ \\
\hline Country Keywords: & United Kingdom Of Great Britain And Northern Ireland \\
\hline & \multicolumn{2}{|l}{} \\
\hline
\end{tabular}


3 North Atlantic circulation indices: links with summer and winter UK temperature and precipitation and implications for seasonal forecasting.

5

Richard J. Hall and Edward Hanna

7 School of Geography and Lincoln Centre for Water and Planetary Health, University of

14 Richard Hall

15 School of Geography

16 Think Tank

17 University of Lincoln

18 Brayford Pool

19 Lincoln

20 LN6 7TS

21 Tel: +44 (0) 1522835384

22 rihall@lincoln.ac.uk 


\section{Abstract}

28 UK seasonal mean temperature and precipitation conditions are extremely variable from

29 one year to the next but in the last decade have featured several cool, wet summers and

30 mild, wet winters interspersed with some notable cold winter episodes. Jet stream

31 variability is a major determinant of these fluctuations, and is often represented by the

32 North Atlantic Oscillation (NAO) index. Recent work has shown some evidence of promising

33 predictability in the winter NAO from one to two months ahead, while summer

34 predictability remains very limited. Although the phase and magnitude of the NAO

35 influences total UK rainfall, there are regional variations which it does not explain. Here we

36 examine the relationship between UK regional summer and winter precipitation and

37 temperature and a range of North Atlantic atmospheric circulation indices. While the NAO

38 shows a significant relationship with temperature in both seasons and summer rainfall over

39 most of the UK, the picture in winter is more complicated with other circulation indices such

40 as the East Atlantic pattern explaining rainfall anomalies in southern England. Other indices

41 also show significant relationships with precipitation in regions where the NAO does not.

42 Since UK weather is determined by the interplay between different circulation indices,

43 attention should be given to developing seasonal forecasts of other circulation indices to

44 complement the NAO forecasts. We also find that some potential drivers of jet stream

45 variability are significantly associated with UK temperature and rainfall variability,

46 particularly in summer. This provides further scope for producing seasonal forecasts based

47 directly on these drivers. Improved seasonal forecasts will be useful to a range of end users

48 in agriculture, energy supply, transport and insurance industries and can be extended to

49 other UK weather variables such as extreme rainfall events and storm frequency, and

50 related metrics such as wind power capacity and solar energy. 
51 Key words: correlation, EOF, jet stream, North Atlantic Oscillation, precipitation, seasonal

52 forecasting, temperature, UK regional climate

53

\section{1. Introduction}

55 UK weather is extremely variable on intraseasonal and interannual timescales, with changes

56 in storminess, wind speeds, rainfall and temperature associated with the variability of the

57 North Atlantic jet stream (e.g. Hulme and Barrow, 1997; Woollings, 2010). Jet stream and

58 associated storm track variability can be represented by the North Atlantic Oscillation (NAO)

59 index (e.g. Vallis and Gerber, 2008; Hanna and Cropper, 2017) and there are strong

60 correlations between jet latitude and the NAO (e.g. Woollings and Blackburn, 2012). The

61 NAO can be defined in several ways, but is often represented as the normalised sea-level

62 pressure (SLP) difference between the Azores, Lisbon or Gibraltar and Iceland (e.g. Hurrell,

63 1995, Jones et al., 1997; Cropper et al., 2015). An increased (decreased, or even reversed)

64 pressure difference results in a positive (negative) NAO phase, the pressure gradient being

65 proportional to the strength of the geostrophic westerlies. The location of the NAO nodes

66 varies over the seasons, and between positive and negative NAO phases (Wanner et al,

67 2001) and this variability can be better captured by an empirical orthogonal function (EOF)

68 approach to identifying the NAO (e.g. Hurrell et al., 2003), with the associated principal

69 component $(\mathrm{PC})$ time series representing the NAO index. Correlation between the Hurrell

70 station-based and PC-based winter (December-February; DJF) NAO indices is 0.88 from

$71 \quad 1899-2016$ whereas for the same period in summer the correlation is only 0.59 ; this reflects

72 the shift in location of the summer centres of action, which is better captured by using EOFs.

73 A summer NAO index (SNAO) has been proposed, partly to reflect this seasonal difference

74 (Folland et al., 2009). As the NAO is equivalent barotropic in nature, it can also be derived 
75 from $500 \mathrm{hPa}$ geopotential height fields and the NOAA Climate Prediction Center (CPC) construct an NAO index based on the rotated EOF of $500 \mathrm{hPa}$ geopotential height anomalies.

77 The NAO can also be identified by one-point correlation maps and cluster analysis, as described by Hurrell and Deser (2009).

In winter, a positive NAO is associated with mild, wet winters in the UK and western Europe,

81 with increased frequencies of stronger westerly winds in the mid-latitudes (Hurrell and

82 Deser, 2010; Burningham and French, 2013) and a positive correlation between

83 temperature and NAO phase over the UK and northern Europe (Comas-Bru and McDermott,

84 2014). Generally there is a north-eastward shift of storm activity, with more storms in

85 northern Europe (Hurrell and Deser, 2009). A more negative NAO generally brings colder,

86 drier conditions to northern Europe. In summer however, there is a poleward shift in the jet

87 stream and the NAO nodes. Consequently a positive summer NAO tends to be associated

88 with warm dry summers in northwestern Europe, low-pressure systems being steered to the

89 north of the British Isles, whereas a negative NAO in summer preferentially directs rain-

90 bearing low-pressure systems over the region (Folland et al., 2009; Dong et al., 2013a).

92 The NAO is the first EOF of SLP over the North Atlantic region. The percentage of variance

93 explained is domain- and time-period dependent, but is greater in winter than in summer

94 and can be typically up to $40 \%$ of total variance (e.g. Hurrell, 1995). However, a significant

95 amount of SLP variance is explained by other lower-order EOFs. The second mode of

96 variability is the East Atlantic (EA) pattern (e.g. Barnston and Livezey, 1987; Moore and

97 Renfrew 2012), which in its positive phase is represented by a low-pressure monopole to

98 the west of Ireland. An EA index with reversed polarity has been used in a number of papers 
99 (e.g. Wallace and Gutzler, 1981; Comas-Bru and McDermott, 2014; Zubiate et al., 2016), but

100 this does not affect the relationships identified, just the polarity. The third EOF, the

101 Scandinavian pattern (SCA), features high pressure over Scandinavia in its positive phase

102 (e.g. Barnston and Livezey, 1987). As with the NAO, the CPC version of these EOFs (EA-CPC

103 and SCA-CPC) are derived from $500 \mathrm{hPa}$ GPH anomalies. The interplay between these modes

104 of atmospheric circulation variability can more fully describe North Atlantic jet stream

105 variability (Woollings and Blackburn, 2012). The percentage of variance explained by these

106 two additional EOFs depends on the time period, domain and atmospheric variable under

107 consideration, but can be up to $25 \%$ for the EA (e.g. Woollings and Blackburn, 2012) and

108 around $10 \%$ for SCA.

110 There has been considerable debate over the extent to which the NAO is purely a mode of

111 atmospheric internal variability, or whether it is driven by external factors. In numerical

112 experiments James and James (1989) found that a mode similar to the NAO can be

113 internally generated, and Feldstein (2000) identified the interannual variability of the winter

114 NAO as arising primarily from unforced climate noise. However the orography of the Rocky

115 Mountains together with the land-sea temperature contrast off the eastern coast of North

116 America, exert an influence on the North Atlantic storm track pattern (Vallis and Gerber,

117 2008; Brayshaw et al., 2009) which in turn impacts upon the NAO phase. Indeed, the NAO

118 changes could be regarded as the variability of the storm track (Vallis and Gerber, 2008).

120 Despite the NAO being a mode of internal variability, there has been recent significant

121 progress in seasonal forecasting of the winter NAO from one to two months ahead, using

122 dynamical forecasting models (Scaife et al., 2014; Stockdale et al.,2015). This is a 
123 consequence of the influence of slowly varying boundary conditions such as North Atlantic

124 and Pacific sea-surface temperatures (SST) and Arctic sea-ice variability, which influence the

125 atmospheric circulation over longer timescales (e.g. Hall et al., 2015; Smith et al., 2016),

126 with the possibility that forecasts can be extended to over a year ahead (Dunstone et al.,

127 2016). Recent statistical forecasts of the winter NAO provide further evidence for this link

128 (Hall et al., 2017a; Wang et al., 2017). A reliable seasonal forecast of the winter NAO will

129 indicate the weather patterns expected in the UK during the upcoming winter months,

130 which is invaluable to planners and decision makers. Several studies demonstrate the

131 potential applications of these forecasts in important areas such as hydrological event

132 prediction (Bell et al., 2017), wind and solar energy supply and energy demand (Ely et al.,

133 2013; Clark et al., 2017) and transport networks (Palin et al., 2016). For example, for a

134 winter forecast of a negative NAO, cold calm weather conditions would be expected

135 together with increased energy demand, yet supply from wind energy will be reduced; a

136 positive NAO forecast would be associated with the probability of increased rainfall and

137 flood risk in certain areas.

139 Seasonal forecasts often focus on the NAO and ignore the contribution of the other

140 circulation indices to temperature and rainfall anomalies, and moreover do not distinguish

141 between UK regional variations, limiting the usefulness of the forecast. There is a significant

142 positive correlation between overall UK winter precipitation and the winter NAO (e.g.

143 Svensson et al., 2015), as a consequence of the shift in storm tracks. However, on a regional

144 basis this is potentially misleading as the heavier precipitation over the north and west, due

145 to orography, frontal rainfall and to geographical location, skews the overall picture (e.g.

146 Comas-Bru and McDermott, 2014). Figure 1 shows rainfall anomaly maps for three recent 
147 positive NAO winters. The distributions of rainfall anomalies are very different, and the 148 generalised positive relationship between NAO strength and UK rainfall is not clear. The 149 rainfall anomaly pattern is not a straightforward function of NAO strength as winter 2014-15 150 has the largest NAO value, yet positive precipitation anomalies are lower and reduced in 151 extent, while areas with negative anomalies increase. In 2015-16, with an intermediate 152 positive NAO value, the largest rainfall anomalies are over the northern UK and 2013-14 has 153 the largest rainfall anomalies over the south of the UK, as well as southern and central 154 Scotland, although the NAO value is the lowest. These positive rainfall anomalies over 155 southern England in 2013-14 have been attributed to the NAO (e.g. Huntingford et al., 156 2014). However, van Oldenborgh et al. (2015) point out that the winter NAO is significantly 157 correlated with rainfall only in the north and west of the UK, and the NAO does not explain 158 rainfall variance in the south. A straightforward NAO forecast for each of these winters, 159 even if accurate, would not predict the observed regional distribution of rainfall anomalies, 160 or indeed their magnitude, based on a linear relationship. Comas-Bru and McDermott

161 (2014) illustrate the effect of the interplay between the NAO and EA on winter precipitation 162 patterns (their Figure 9), indicating that the EA phase plays an important role in determining 163 regional variability of precipitation anomalies under positive NAO conditions. Figure 2 164 shows SLP and zonal wind differences between 2013-14 and 2014-15. The North Atlantic jet 165 is stronger in the former, and displaced southward, despite the lower NAO value. In figure $1662 \mathrm{~b}$, a clear EA pattern emerges, indicating a more positive EA in 2013-14. There is also a 167 contribution from the positive SCA pattern in 2013-14 relative to 2014-15. Therefore it is 168 evident that the regional rainfall anomalies of a particular season cannot be attributed 169 solely to the NAO. 
171 At present there is little skill in forecasts for the summer North Atlantic atmospheric

172 circulation, yet such skill would be of particular benefit to the agricultural and leisure

173 sectors. However, a recent study has identified some possible sources of predictability (Hall

174 et al., 2017b). Decreased (increased) sea-ice extent in the Barents-Kara Sea is associated

175 with a southward (northward) displacement of the jet in the following summer, which may

176 be related to the persistence of sea-ice thickness anomalies through the winter (Blanchard-

177 Wrigglesworth et al., 2011). The recent cool wet UK summers (e.g. Blackburn et al., 2008;

178 Dong et al., 2013b) have also been associated with the positive phase of the Atlantic

179 Multidecadal Oscillation (AMO) of Atlantic-wide SST anomalies (e.g. Sutton and Dong, 2012).

181 In this study we explore the relationships between a number of North Atlantic atmospheric

182 circulation indices and temperature and rainfall over the UK, for both summer (JJA) and

183 winter (DJF), in order to inform the future development of seasonal forecasts that are

184 tailored to specific regions of the UK. We also identify some potential links between

185 identified drivers of jet stream variability and precipitation and temperature over the UK,

186 which may further enhance seasonal forecasting potential. Section 2 describes the data

187 used, methods are outlined in section 3 and results presented in section 4 . Section 5

188 contains a wider discussion of the results and a summary follows in section 6.

191 A summary of datasets, time periods and regions extracted is given in Table 1. Gridded

192 rainfall and temperature data for the UK are available at $5 \mathrm{~km}$ resolution (UKCP09; Perry and 193 Hollis 2005). These are based on observations and use regression to fill gaps in station data 194 and inverse-distance weighted interpolation of regression residuals to generate values on a 
195 regular grid, considering factors such as latitude, longitude, altitude, coastal and urban 196 influences. In addition, regional rainfall and temperature records for the UK are available

197 from the Met Office. A time series of monthly precipitation for UK regions (HadUKP;

198 Alexander and Jones, 2001) is also used. These regions (Figure S1) are based on areas of

199 coherent precipitation variability (Wigley et al., 1984). The Central England Temperature 200 index (CET; Manley, 1953; Parker et al., 1992) and regional HadUKP data are used for

201 comparison with UKCP09 gridded data in order to identify associations with atmospheric 202 circulation indices.

204 The NAO, EA and SCA indices are available from the CPC. These are time series derived from 205 the rotated EOFs of 500hPa GPH anomalies, based on the NCEP/NCAR reanalysis (Kalnay et 206 al., 1996) over the whole of the Northern hemisphere

207 (http://www.cpc.ncep.noaa.gov/data/teledoc/ea.shtml). The summer NAO (SNAO) is the 208 first EOF of SLP over 40-70N, 90W-30E, using NCEP/NCAR data, and is available from Climate 209 Explorer (www.climexp.knmi.nl). In addition, the first three EOFs of North Atlantic SLP and 210 their principal component (PC) time series are calculated for summer and winter over 1951-

2112014 using 20CRv2c SLP data (Compo et al., 2011) and for 1979-2016 using ERA-Interim

212 (ERA-I) reanalysis data (Dee et al., 2011). Separate EOFs are calculated for 1979-2014 (1980-

2132014 for DJF) from both 20CRv2c and ERA-I to allow a direct comparison between EOFs

214 from different reanalyses for the same time period. The area used is $20-80 \mathrm{~N}, 90 \mathrm{~W}-40 \mathrm{E}$

215 which is identical to the area used for the Hurrell PC NAO index; new indices are calculated

216 to ensure that the first three EOFs are available and orthogonal. SLP is chosen since 20CRv2c

217 uses SLP observations as a boundary condition and therefore SLP data are likely to be more 218 accurate than $500 \mathrm{hPa}$ GPH. Finally, the Hurrell station-based NAO index is used as an 
219 example of a station-based index and is described in the NCAR/UCAR Climate Data Guide

220 (www.climatedataguide.ucar.edu).

221

222 Metrics of jet speed and latitude variability are derived according to Woollings et al. (2010).

223 Daily zonal wind speeds over $700-900 \mathrm{hPa}$ from the North Atlantic region $\left(16-76^{\circ} \mathrm{N}, 60-0^{\circ} \mathrm{W}\right)$

224 are averaged vertically and a zonal-mean wind speed is calculated for each $2^{\circ}$ latitude band.

225 The maximum zonal mean gives the speed of the jet for each day, while the jet latitude is

226 given by the latitude at which this maximum occurs. The daily time series of jet speed and

227 latitude are filtered using a 61-point Lanczos filter to remove synoptic-scale variability

228 (Duchon, 1979) and seasonal values of jet speed and latitude are calculated. Jet latitude and speed time series use ERA-I for 1979-2016 (JJA), 1980-2016 for DJF, and a longer time series uses 20 CRv2c for 1951-2014. The ensemble mean values are used from 20CRv2c, as post1950 the ensemble spread is much reduced, and are in close agreement with jet metrics from other reanalysis products (e.g. Woollings et al., 2014). 850hPa vector winds and 925hPa air temperature anomalies are obtained from NCEP/NCAR reanalysis (Kalnay et al., 1996) for 1951-2016 and are used in composites of high and low circulation index years, to identify atmospheric features associated with the indices.

237 To identify any associations between drivers of jet variability and UK rainfall and temperature, datasets of key drivers are used as identified by Hall (2016) for winter and Hall et al. (2017b) for summer. Both use multiple regression, composite and wavelet coherence

240 analysis to determine potential drivers of jet speed and latitude. Hall (2016) identifies January AMO and Atlantic and Pacific tropical precipitation as drivers of winter jet speed.

242 Drivers of winter jet latitude include the October N3.4 index, November sea-ice 
243 concentration in the Barents-Kara Seas, October Eurasian snowcover and the autumn Quasi-

244 biennial oscillation (QBO). Sea-ice concentration is obtained for the Greenland Sea (GI) and

245 Barents-Kara Sea regions (BKI), from the HadISST1 dataset (Rayner et al., 2003). Snowcover

246 data from Eurasia and North America are obtained from Rutgers University Snow Lab

247 Robinson et al., 2012; http://climate.rutgers.edu/snowcover/). Two indices represent

248 Atlantic SST: (1) AMO (Enfield et al., 2001) index data are obtained from the Earth System

249 Research Laboratory (www.esrl.noaa.gov/psd/data/timeseries/AMO) based on the Kaplan

250 SST dataset (Kaplan et al., 1998, updated); (2) A North Atlantic tripole index uses the

251 methodology of Czaja and Marshall (2001), based on the HadISST1 SST anomaly taken over

$25260-40^{\circ} \mathrm{W}, 40-55^{\circ} \mathrm{N}$, minus the anomaly over a southern region $80-60^{\circ} \mathrm{W}, 25-35^{\circ} \mathrm{N}$. Anomalies

253 are relative to the 1981-2010 climatology. Monthly sunspot numbers are obtained from the

254 Solar Influences Data Analysis Center (http://sidc.oma.be/). The QBO data are obtained

255 from the Free University of Berlin (www.geo.fu-berlin.de/en/met/ag/strat/produkte/qbo/;

256 Naujokat, (1986), updated). Tropical central Pacific SST anomalies are represented by a

257 discontinuous El-Nino 3.4 index (N3.4) as described in Folland et al. (2012), derived from

258 HadISST1 data. Tropical Atlantic precipitation anomalies from the Global Precipitation

259 Climatology Project (GPCP v2; Adler et al., 2003) are also used. All these drivers are taken

260 from 1951-2016, with the exceptions of snow cover and tropical precipitation, which are

261 available from 1979. Figure S2 shows these regions.

263 All datasets are linearly detrended to isolate the interannual association between circulation

264 indices and temperature and rainfall. Winters are labelled by the year of the January,

265 following standard meteorological convention.

266 


\section{Methods}

268 In order to identify the dominant North Atlantic atmospheric circulation patterns that

269 influence UK weather on a seasonal scale, EOFs of North Atlantic SLP are constructed using

270 latitude weightings (multiplying by the square root of the cosine of latitude). The

271 significance of the separation of the EOFs is assessed using North's Rule of Thumb (North et

272 al., 1982). For winter and summer, the first three EOFs are found to be distinct. The EOF

273 patterns also illustrate changes in circulation patterns between summer and winter. The

274 principal components (PCs) are used as circulation indices for comparison with NAO-CPC,

275 EA-CPC and SCA-CPC, as well as with metrics of jet speed and latitude.

276

277 A simple correlation analysis (Pearson's Product Moment) is conducted to identify

278 relationships between the circulation indices themselves and associations between

279 circulation metrics and UK temperature and rainfall. Significance is calculated based on

280 effective degrees of freedom according to Bretherton et al. (1999), allowing for temporal

281 autocorrelation in the time series. In addition, spatial autocorrelation and issues associated

282 with multiple testing occur with correlation maps, which lead to areas of significance being

283 too extensive due to overestimation of the number of spatial degrees of freedom. To

284 minimise this effect the False Discovery Rate (FDR, Benjamini and Hochberg, 1995) is used.

285 The $p$-values of the $N$ tests are ordered. The smallest and nominally most significant of

286 these tests is denoted $p_{(1)}$ and the largest and least significant is $p_{(N)}$. Individual tests are

287 taken as significant if the corresponding $p$-value is no greater than:

288

$$
p_{F D R}=\underset{j=1, \ldots, N}{\max }\left\{p_{j}: p_{j} \leq \frac{j}{N} \alpha_{\text {global }}\right\}
$$


290 The sorted $p$-values are assessed on a sliding scale. If the largest, $p_{(N)}$ is no greater than

$291 \alpha_{\text {global }}=F D R$, all the tests are taken as being significant. The null hypothesis is rejected for the

292 test having the largest $p$ value satisfying equation 1 , as are the null hypotheses for all tests

293 with smaller $p$-values (Wilks, 2011; pp180-181).

294

295

Composites of vector wind and air temperature anomalies are obtained for the ten highest

and lowest circulation index years from the detrended time series, to identify larger-scale

297

atmospheric circulation features associated with the circulation indices and UK precipitation

and temperature patterns, in order to explain particular patterns of precipitation and

temperature correlation with circulation indices.

Correlation is also used to determine the strength and sign of association between

identified drivers of North Atlantic jet stream variability and UK precipitation and temperature.

304

\section{Results}

306

\subsection{EOF analysis of North Atlantic SLP}

307 The EOFs derived from 20CRv2c for 1951-2014 are shown in Figure 3. Figures S3 and S4

308 show the equivalent for 20CRv2c and ERA-I, for 1980-2014 (DJF) and1979-2014 (JJA). For all

309 periods, the first EOF is clearly recognisable as the NAO (SNAO in summer; Figures 3a,d;

$310 \mathrm{S3a}, \mathrm{d} ; \mathrm{S} 4 \mathrm{a}, \mathrm{d})$. For the longer period, in summer EOF3 bears a closer resemblance to the EA

311 than does EOF2 (Figure 3e,f), whereas in winter it is EOF2 that most closely resembles the

312 EA, and EOF3 the SCA, although the high-pressure centre is displaced westwards compared 
313 to the classic SCA (Figure 3b,c). The wintertime EOF2/EA and EOF3/SCA agreement is

314 evident in EOFs from both reanalyses from 1980 onwards, (Figure S3), although there is a

315 suggestion that EOF3 for both reanalyses (Figure S3c,f) could be a better fit for the East

316 Atlantic-West Russian pattern which is often identified as the fourth EOF of North Atlantic

317 atmospheric pressure or GPH, characterised by a wavelike pattern extending from the

318 south-west to north-east (e.g. Lim, 2015). In summer the picture is less clear-cut for the

319 period from 1980, with EOF2 resembling a combination of EA and SCA in both reanalyses

320 (Figure S4b,e), while the two EOF3s are very different (Figure S4c,f). It is actually EOF4 of

321 ERA-I that most closely resembles EOF3 of 20CRv2c and SCA (not shown). This variation

322 among the first three EOFs of SLP reflects a number of factors. First, different domains and

323 time periods used for computing EOFs will introduce variations, particularly with the lower-

324 order EOFs. There will also be differences between EOFs calculated using SLP and 500GPH.

325 EOFs do not reflect change over time and are stationary, and therefore EOFs calculated for

326 different time periods are likely to reflect differences in relative strength between the EOFs,

327 and changes in intensity and location of centres of action. Further differences between the

328 EA-CPC and SCA-CPC patterns and the EOFs and PCs calculated here are attributable to the

329 former being calculated through rotated EOFs for the whole of the northern hemisphere. It

330 is notable that while spatial patterns are similar for 20CRv2c and ERA-I EOFs (Figures S3, S4),

331 the amplitude of the EOFs in ERA-I is much less. Using NCEP/NCAR reanalysis produces

332 amplitudes similar to those for 20CRv2c (not shown), and the reasons for the ERA-I

333 discrepancy are unclear at present.

\subsection{Relationships between Atlantic Circulation Indices}


336 The correlations between the circulation indices for 1951-2014 and 1979-2016 are shown in

337 Table 2. There is good agreement between correlations over the two time periods;

338 however, some discrepancies occur between PC2 and PC3, particularly in summer, reflecting

339 the differences identified above between the EOF spatial patterns. For winter there is

340 agreement between the identification of PC2 and PC3 over the two different time periods.

341 In summer, by contrast, PC2 and PC3 are exchanged between the two time periods, as

342 indicated by the EOF patterns in Figures 3 and S4. The EA-type pattern may have become

343 more significant in the latter period in summer, promoting it to EOF/PC2. This switching of

344 EOFs could be modulated by low-frequency SST variability such as the AMO. The latter has

345 been in a positive phase since the mid-1990s and positive SST anomalies will be associated

346 with lower SLP west of Ireland, corresponding to a positive EA. The summer EA has been

347 largely positive since 2000.

349 In winter for the period 1951-2014, there is good agreement between the different NAO-

350 like indices (NAO-CPC, PC1, Hstat, $r=0.89-0.94$ ) and jet latitude correlates highly with all

351 three $(0.77,0.82$ and 0.79 respectively), indicating that the NAO-like circulation indices all

352 capture more than $60 \%$ of the variance of winter jet latitude $\left(R^{2}\right)$. EA-CPC correlates well

353 with PC2 (0.82) and with both jet speed and latitude ( 0.53 and -0.57 respectively), in

354 agreement with Woollings and Blackburn (2012). SCA-CPC shows a significant negative

355 correlation with jet latitude (-0.29) while the correlation with jet speed is insignificant. The

356 correlation between SCA-CPC and PC3 is 0.35 , notably weaker than the correlation between

357 PC2 and the EA-CPC; therefore PC3 from this analysis is similar but not equivalent to SCA-

358 CPC. All leading modes of variability contribute to jet latitude variance (CPC: NAO 59.3\%, EA: 
$35933 \%$, SCA: $8 \%$; note here the variance total for the first three EOFs slightly exceeds $100 \%$ as

360 rotated EOFs and their PCs are non-orthogonal).

361

362 In summer, from 1951-2014 the association between NAO-like indices is weaker. Correlation

363 coefficients are between 0.81 and 0.90 for pattern-based EOF indices (NAO-CPC, PC1, SNAO)

364 while those of the NAO-CPC, PC1 and SNAO with Hstat are $0.47,0.53$ and 0.27 , reflecting

365 the shift in the NAO nodes in summer, which is not well captured by the fixed-point station-

366 based approach. PC1, NAO-CPC, SNAO and jet latitude are portraying essentially the same

367 atmospheric circulation variability. The station-based index is not as strongly correlated with

368 jet latitude (0.37) confirming the deficiency of this type of index in representing summer jet

369 stream variability. As with winter, the EA-CPC shows a similar strength but opposite sign of

370 correlation with jet speed and latitude.

371

372 PC2 represents a mix of EA and SCA while PC2 and PC3 are well correlated with summer jet

373 speed $(-0.53,0.59)$ compared with 0.36 and -0.07 for EA-CPC and SCA-CPC. The correlations

374 for 1979-2016 show general agreement with those for the longer period, although the

375 exchange of PC2 and PC3 is evident in the correlations. Jet speed and latitude are not

376 significantly correlated in either season, indicating that different factors may influence their

377 variability (Woollings et al., 2010).

379 4.3. Relationships between North Atlantic circulation indices and UK regional temperature 380 and precipitation

381 Correlations between the full range of atmospheric circulation indices and regional

382 temperature and precipitation are presented in Table 3. Correlation maps based on 
383 circulation indices and temperature and precipitation from UKCP09 (Figures 4-7) illustrate

384 the spatial patterns of correlations, which is particularly important for temperature as CET

385 only covers central England and gives no indication of regional variations. Only one map is

386 shown for indices relating to jet latitude variability (PC1); maps for similar indices such as jet

387 latitude, NAO-CPC and SNAO show little qualitative difference to that shown here.

\subsubsection{Temperature}

390 Correlations of the indices of jet latitude (NAO-CPC, PC1, Hstat, SNAO) with CET are positive and significant in both seasons, with the exception of Hstat in summer (Table $3 a, b)$. In winter, EA-CPC, SCA-CPC and PC3 show no significant correlation with CET, while PC2 has a positive correlation. In summer, EA-CPC has a significant negative correlation with CET, PC3 shows no significant relationship and PC2 is significantly positively correlated with CET although SCA-CPC is not.

In Figures 4 and 5, EA-CPC, SCA-CPC and PC3 have no significant correlations with winter temperature over the whole of the UK (Figure 4a,b,e). However, PC2 shows significant positive correlations in the southern half of the UK (Figure 4d); a similar pattern to that shown by the EA-CPC but with stronger correlations and similar to the correlation pattern for jet speed (Figure 4f), reflecting the strong correlation between jet speed and PC2 (0.73) in Table 2. PC1 has positive significant correlations with winter temperature over the whole of the UK (figure 4c), and these associations get stronger to the north and west.

405 While winter temperature correlations reveal a north-south variation (Figure 4), those in 406 summer have a more meridionally-oriented variability (Figure 5). The EA-CPC has significant 
407 negative correlations with temperatures in the west of the UK (Figure 5a), while PC1 is

408 positively correlated with temperature for all the UK except western Scotland, although

409 correlations are less strong than in winter (Figure 5c). Correlations with SCA-CPC, PC3 and

410 jet speed are insignificant. Interestingly, PC2 which has a correlation of 0.43 with SCA-CPC

411 (Table 2), shows significant positive correlations with summer temperature over all but

412 eastern East Anglia and the North Sea coast of Lincolnshire and Yorkshire (figure 5d).

\section{$414 \quad$ 4.3.2 Precipitation}

415 In winter significant positive correlations occur for Scotland and Northern Ireland

416 precipitation with jet latitude-related metrics (NAO-CPC, jet latitude, PC1,Hstat; Table 3a),

417 while there are significant negative correlations with eastern and southern England

418 precipitation, clearly seen on Figure 6c. For large parts of the Midlands, Wales and south-

419 west England, the NAO has no significant correlation with precipitation as either a

420 northward or southward shift in the jet will steer low pressure systems away from this

421 region. The negative correlations on the eastern side of the UK are due to these regions

422 lying in the rain shadow of the prevailing westerlies under a positive NAO, while for a

423 negative NAO, anomalous easterly winds may bring moisture off the North Sea as

424 precipitation along the east coast. PC2 and EA-CPC have significant positive correlations

425 with precipitation across England and Wales, with correlations being stronger for PC2,

426 significant correlations extending to western Scotland and northwest England and the whole

427 of Northern Ireland (Figure 6a,d). SCA-CPC and PC3 show significant negative correlations

428 with precipitation, mostly over the northern and western UK regions, which are stronger

429 and more extensive for PC3 (Figure6b,e), significance for SCA-CPC being restricted to the

430 northwest of Scotland. Jet speed has a similar correlation pattern to PC2 and EA-CPC, but 
431 with a more westerly focus, insignificant correlations stretching down the east coast of 432 England (Figure 6f).

433

434 For summer, the indices that primarily represent jet latitude variability (NAO-CPC, latitude, 435 PC1 and SNAO) show almost exclusively significant negative correlations with regional 436 precipitation (Table3b, Figure 7c), regardless of region although only SNAO has a significant 437 correlation in the north of Scotland. The summer EA-CPC more closely resembles PC3 and 438 both have positive significant relationships with precipitation (Table 3b, Figure 7a,e), these 439 being stronger and with more widespread significance for the EA-CPC, although this

440 significance appears patchy in southeast England and the extreme north west of Scotland

441 (Figure 7a). PC2 and SCA-CPC show negative correlations with rainfall, significant for both

442 indices in Scotland and with some significance over north-west England, Wales and

443 Northern Ireland for PC2 (Figure 7b,d). Jet speed has a significant positive correlation with 444 precipitation in the west of Scotland, precisely where the PC1 correlations are insignificant 445 (Table 3b, Figure 7f).

446

\subsection{Explaining features of North Atlantic circulation-UK regional climate correlations.}

448 Composites of vector wind and 925hPa air temperature anomalies (Figures 8 and 9) yield

449 important features of the North Atlantic atmospheric circulation that explain the 450 correlations discussed above. Figures show high minus low index years, indicating 451 conditions under a positive circulation index. 
454 In winter, the positive correlations of EA-CPC/PC2/jet speed with temperature over south

455 and central England (Figure 4a,d) are associated with south westerly wind anomalies

456 advecting warmer air over the UK (Figure 8a-d,k,l) for the positive phase EA-CPC/PC2. For

457 PC2 warm anomalies extend to North Africa and are slightly stronger over western Europe

458 compared with EA-CPC (Figure 8b,d): hence the significant correlations with temperature in

459 Figure 4d. In contrast, for SCA/PC3 anomalous easterly winds advect cold air from

460 continental Europe over the UK, leading to lower temperatures (Figure 8e-h) and thw weak

461 negative correlations with temperature (Figure 4b,e). SCA-CPC and PC3 are associated with

462 anomalously low temperatures over central Asia (not shown), although the centre of this is

463 shifted westwards for PC3 and temperatures are not as low $\left(60^{\circ} \mathrm{E},-4.0^{\circ} \mathrm{C}\right.$ for $\mathrm{PC} ; 90^{\circ} \mathrm{E},-$

$4646.4^{\circ} \mathrm{C}$ for SCA-CPC). Under positive NAO conditions (PC1), strong westerly wind anomalies

465 advect relatively warm maritime air over the UK, and into northern Europe (Figure 8i,j).

467 While winter correlations with temperature change in a north-south direction, those in

468 summer change from east to west, which is explained by summer changes in circulation

469 patterns and the locations of regions of anomalous temperature (Figure 9). The EA-CPC

470 (Figure 9a,b) and jet speed (Figure 9k,I) are negatively correlated with temperatures in the

471 west of the UK, correlations being significant for the EA-CPC (Figure 5a). Both circulation

472 patterns show a negative temperature anomaly over the central North Atlantic (positive EA,

473 stronger jet), but the centre of this is located directly over the UK for the EA-CPC, exerting a

474 stronger influence on UK temperatures than for jet speed (Figure 9b, c.f. 9l). For PC3, (Figure

$4759 \mathrm{~g}, \mathrm{~h}$ ) while the circulation pattern is similar to that of the EA-CPC, it is displaced westwards,

476 the mid-Atlantic cold anomaly is further west and winds over the UK are south-westerly,

477 with insignificant correlations between the circulation pattern and regional temperature 
478 anomalies (Figure 5e). Vector winds suggest the cold anomaly for EA-CPC originates with the 479 southerly advection of cold air from Iceland and Greenland (Figure 9a), and in the case of jet 480 speed, from the Baffin Bay region (figure 9k), whereas for PC3, there is evidence of mixing of 481 cold Greenland air with air drawn up from the Gulf of Mexico, reducing the impact of the 482 negative temperature anomaly (Figure 9g). The PC2/SCA-CPC patterns are associated with 483 positive UK temperature anomalies (Figure 9d,f), with easterly wind anomalies bringing in 484 warm continental air. The easterlies are stronger for PC2 and the warm continental anomaly 485 extends further west over the UK. The lack of significant correlation between temperature 486 and PC2 along the North Sea coast of England (Figure 5d) is likely to be due to local conditions, where Haar fog is frequently experienced as warm air flows over the cold North Sea, cooling areas along the coast and adjacent areas.

In the positive phase of PC1 (or SNAO), the southern UK lies under an anomalous easterly flow of warm continental air, leading to anomalously warm conditions, while north-west Scotland lies under the westerly jet (Figure 8i), advecting cooler air from the North Atlantic and weakening the correlation with temperature in this region (Figure 5c) .

\subsubsection{UK Precipitation}

496 The positive winter correlation between southern UK precipitation and the EA-CPC/PC2/jet

497 speed is explained by the moisture-laden south-westerlies, with their main focus on the southern regions of the UK (Figure 8a,c,k). Conversely, for a positive phase of PC1, the jet stream lies over the northern half of Britain (Figure 8i), with heavier rainfall over western

500 Scotland and north-west England, but with an east/west divide caused by the orographic 501 impact on rainfall, and the rain-shadow effect (Figure 6c). The rainfall correlation pattern for 
502 SCA-CPC/PC3 is almost the reverse of the PC1/NAO pattern (Figure 6b,e), with significant

503 positive relationships along the east coast as easterly winds bring moisture from the North

504 Sea, while the western regions are in the rain-shadow with respect to these easterlies. The

505 effect may be more pronounced for the SCA-CPC relative to PC3 as the easterly winds are

506 displaced northwards and have a longer fetch across the North Sea (Figure 8e,g).

507

508 In summer, the positive association of precipitation with the EA-CPC/PC3/jet speed is

509 governed by the warm moist westerlies, with the northward displacement of westerlies for

510 a strong jet speed (Figure 9k), combined with the orographic effect accounting for the

511 significant positive correlations in the western Scotland (Figure 7f). Significant positive

512 correlations with the EA are more widespread, with warm moist air being drawn from

513 further south in the central North Atlantic (Figure 9b,k). The cold anomalies over the UK

514 during the positive EA-CPC phase (Figure 9b) may encourage condensation of water vapour

515 in the warm moist Atlantic air, increasing precipitation. SCA-CPC and PC2, have a negative

516 correlation with precipitation along the west of the UK, similar to that in winter (Figure

$5177 b, d)$. The areas of significance are more extensive in PC2 due to the stronger area of high

518 pressure evident over the North Sea compared with SCA-CPC (Figure 9c,e).

519

520 The lack of significant summertime correlation between precipitation and the NAO in north-

521 west Scotland (Figure 7c) is due to the summertime northward shift in the NAO centres of

522 action (Figure 3a,b); for a positive SNAO/PC1, north-west Scotland is just south of the main

523 storm track whereas for a negative phase, it lies just to the north, hence the change in

524 rainfall will not be as great as further south, where in the positive phase the southern UK is 
525 well to the south of the storm track, experiencing low rainfall, while in a negative phase, the 526 storm track directs low pressure systems toward this region.

5284.5 Drivers of Jet Variability and their relations with UK regional temperature and 529 precipitation patterns.

530 Table 4 shows correlations between slowly varying drivers of jet stream variability and UK 531 temperature and precipitation. It is unsurprising that many of the jet stream drivers are 532 insignificantly correlated with rainfall or temperature, as any influence is indirect, operating 533 through jet variability. Each driver is only one of several jet predictors, which together 534 explain only a fraction of jet variance. The jet in turn only explains a fraction of precipitation 535 and temperature variance. However, there are some notable significant correlations, 536 particularly in summer. Detrended November sea-ice concentration in the Barents-Kara Sea 537 (BKI) has significant negative correlations with summer rainfall over the whole of the UK 538 with the exception of Northern Scotland, and a significant positive correlation with CET

539 (Table 4b). The sign of the relationships is as expected from the positive association 540 between November sea-ice and summer jet latitude; reduced sea-ice is associated with a 541 southward displacement of the jet in the following summer, with increased rainfall and

542 cooler temperatures. Correlations between November BKI and the summer temperature

543 and rainfall are almost identical over the periods $1955-2014$ ( 0.27 for CET and -0.39 for

544 EWP) and 1979-2016 (0.31; CET and -0.39; EWP), suggesting the relationship is not

545 attributable to recent sea-ice decline.

547 The positive summer association of precipitation with the AMO, as identified by Sutton and 548 Dong (2012) is significant over northern England, Scotland and Northern Ireland (Table 3b), 
549 although not significant further south. The result is consistent with O'Reilly et al. (2017),

550 who identify similar associations between precipitation and the AMO phase, which is

551 dynamical in origin, associated with a cyclonic SLP anomaly over the North Atlantic, leading

552 to increased precipitation over northwestern Europe.

553

554 The lagged negative association between summer precipitation and the solar cycle is

555 significant in the south-east of England and eastern Scotland, and England and Wales more

556 generally. While the lag agrees with recent studies (Scaife et al., 2013; Gray et al., 2013;

557 Andrews et al., 2015), these all focus on winter. The lagged solar relationship was not

558 identified as a significant driver of winter jet variability in Hall (2016) and so is not examined

559 here; it is beyond the scope of this paper to test direct associations between a larger

560 number of predictors and UK temperature and precipitation. The significant positive

561 correlation of Scottish precipitation with January tropical Atlantic precipitation (AR; Table

$5623 \mathrm{~b}$ ) is as-yet unexplained and could be down to chance, although it was identified as a driver

563 of JJA jet speed (Hall et al., 2017b), which has similar positive correlations with Scottish

564 rainfall (Table $2 \mathrm{~b}$ ). It is surprising that correlations in winter are fewer and weaker, whereas

565 predictability of the NAO is greater in winter (e.g. Scaife et al., 2014). This could reflect the

566 increased number of drivers operating in winter, which may mean correlations with

567 individual drivers are weak, or are better represented by factors not included here such as

568 the strength of the stratospheric polar vortex.

569

570 5. Discussion

571 The results presented here demonstrate the limited value of NAO winter seasonal forecasts,

572 when considering UK regional temperature and precipitation variability. The use of forecast 
573 of other circulation indices such as the EA, SCA and jet speed and latitude can complement

574 the NAO forecasts, and help to provide a more regional focus. Results agree with van

575 Oldenborgh et al. (2015) who identified that the southern England precipitation anomalies

576 in 2013/14 cannot be attributed to the NAO. Similarly, Wood (2004) reports that although

577 the NAO is a good indicator of winter temperature in the south west of England, there is a

578 less clear association with precipitation, also shown in this study (Figures 4c, 6c). Comas-Bru

579 and McDermott (2014) show similar regional variations in the strength of association

580 between NAO phase and winter precipitation and temperature.

581

582 Results presented in this study indicate that in $2013 / 14$, precipitation anomalies in southern

583 England can be attributed to the positive EA phase (Figure 6a) and to the strong jet stream

584 which will itself strengthen the EA (Figure 6f). Returning to Figure 1, only 2014/15 shows a

585 classic NAO distribution of winter precipitation anomalies (see Figure 6c), although the

586 positive rainfall anomalies are not as large as those in $2013 / 14$ and $2015 / 16$. Other winters

587 demonstrating the classic NAO pattern since 2000 are 2001/02, 2004/05, 2011/12 (positive

588 NAO), and 2002/03 and 2009/10 (negative NAO). All other years show patterns that are

589 significantly influenced by other circulation regimes. Similarly, recent summers that show an

590 NAO rainfall anomaly pattern as suggested by Figure 7c are 2004, 2007, 2008, 2012 (all

591 negative NAO). Extending the work to the Atlantic basin, Seierstad et al. (2007) find that the

592 NAO does not explain all the storminess in the Atlantic, with the East Atlantic pattern being

593 a significant factor, particularly where the NAO influence is less strong, explaining the link

594 between the EA and southern England precipitation.

595 
596 Statistical models have shown good success in predicting the winter NAO (Hall et al., 2017a)

597 and recent work has also begun to identify some possible sources of predictability in the

598 summer jet latitude and speed (Hall et al., 2017b). These influences on the jet stream, and

599 by definition the NAO, are sources of potential predictability of both the winter and summer

600 North Atlantic atmospheric circulation and UK regional temperature and rainfall anomalies.

601 The weak correlations between a number of these influences and UK rainfall and

602 temperature found here are unsurprising. Each driver is only one contributory factor to NAO

603 variance, and a combination of drivers will only explain around $35 \%$ (summer) to $56 \%$

604 (winter) of the NAO variance (Hall et al., 2017b, Hall, 2016). Likewise the NAO will only

605 "explain" a limited portion of the rainfall or temperature variance. Any causality is one step

606 removed, meaning correlations between NAO drivers and rainfall and temperature are likely

607 to be lower than correlations between the driver and NAO itself. However, there are

608 promising correlations between a number of drivers of summer jet stream variability,

609 particularly November BKI, the AMO and a lagged solar influence, and UK summer rainfall

610 and temperature. The mechanism for a summer lagged solar effect is unclear, as recent

611 studies identify an association in winter, with a suggested coupling between ocean and

612 atmosphere (Scaife et al., 2013; Gray et al., 2013). This involves storage of heat in the ocean

613 from winter below the shallow summer thermocline, which re-emerges as the latter breaks

614 down in the following winter. However, in Andrews et al. (2015) these positive temperature

615 anomalies are shown persisting in the summer mixed layer of the ocean for up to four years

616 (their figure $4 \mathrm{~b})$. The sea-ice association has also to be explained and may depend on

617 persistence of SST anomalies induced by the previous season's ice anomaly. This is an area

618 for future research, together with examining associations with a wider range of drivers than 
619 used here, such as the stratospheric polar vortex in winter. It may be possible to use these

620 slowly varying boundary conditions to make direct forecasts of UK seasonal weather.

621

622 Developing effective statistical models for the EA-CPC/PC2 and SCA-CPC/PC3 and jet speed

623 will identify further potential sources of seasonal predictability for these indices, which in

624 turn will allow more accurate regional seasonal forecasts of temperature and precipitation

625 to be issued, for both summer and winter. Such models may in turn inform the next

626 generation of dynamical weather forecasting models. Forecasts could also be extended

627 from meteorological variables to more specific metrics used by the power generation

628 industries. For example, high electricity demand in winter is driven by cold conditions,

629 frequently associated with high pressure and anomalous easterly winds prevalent under a

630 negative NAO or SCA-CPC/PC3 pattern. Thornton et al. (2017) find that peak demand is

631 associated with a SCA-CPC/PC3 type circulation, while the wind capacity for electricity

632 generation actually increases slightly under these conditions, compared with when high

633 pressure and low wind speeds are situated directly over the UK. Therefore SCA-CPC/PC3

634 forecasts could also be associated with wind capacity metrics and would be useful for the

635 wind power industry. Similarly, solar energy generation from photovoltaic (PV) cells is

636 dependent on sunshine duration and cloud cover, which can also be related to the phase of

637 the NAO on a regional basis, (e.g. Colantuano et al., 2014) and may also be associated with

638 other circulation regimes in different parts of the UK. However, a cautionary note should be

639 sounded. Non-stationarities are evident in the NAO and other circulation patterns, due to

640 shifts in centres of action, changes in frequency of occurrence of particular patterns and

641 changes in the preferred phase of the patterns (Hertig et al., 2015). Such non-stationarities

642 are likely to result in changes in the strength of association over time between the 
643 circulation patterns and meteorological variables, which will have an impact on regional

644 climate predictability. This study also demonstrates that a station-based NAO is not well-

645 correlated with summertime UK temperature and precipitation, due to shifts in the NAO

646 centres of action during the summer, away from the traditional station locations. Therefore

647 summer seasonal forecasts should focus on jet speed and latitude, or PC-based circulation

648 indices.

649

650 6. Summary

651 These results demonstrate that UK-wide regional variations in temperature and

652 precipitation anomalies are not adequately explained by the NAO alone. The NAO is

653 primarily an indicator of jet latitude variability, here described by a range of indices (NAO-

654 CPC, Hstat, PC1, and in summer, SNAO). In summer, the NAO is positively (negatively)

655 correlated with temperature (precipitation) over the whole of the UK with the exception of

656 northwest Scotland. In northwest Scotland, however, rainfall is most strongly correlated in

657 summer with jet speed and negatively correlated with PC2/SCA-CPC. In winter, while

658 temperatures are significantly positively correlated with the NAO over the whole of the UK,

659 precipitation predictability based on the NAO only applies to northwest of Scotland and

660 England (significant positive correlation), and the east coasts of Scotland and England,

661 where the correlation is negative. Significant correlations for the rest of the UK come from

662 other atmospheric circulation indices: most notably PC2, PC3 and jet speed. Therefore,

663 developing seasonal forecasts for a range of North Atlantic atmospheric circulation metrics

664 would be advantageous for providing improved regional seasonal forecasts of precipitation

665 and temperature, although the NAO is the most effective index in terms of predicting UK 
666 temperature anomalies. Seasonal forecasts could be extended to include other

667 meteorological variables and related metrics such as those used by the energy industries.

668

669 Acknowledgements

670 We thank ECMWF, NOAA/OAR/ESRL PSD for providing the ERA-I, 20CRv2c and NCEP/NCAR

671 reanalyses and CPC time series and the Met Office for providing UKCP09, HadUKP and CET,

672 We acknowledge useful discussions with Adam Phillips at UCAR concerning EOFs and the

673 three anonymous reviewers whose helpful comments significantly improved the

674 manuscript.

675

676

\section{Supporting Information}

678 Figure S1. UK precipitation regions

679 Figure S2. Locations of drivers of jet stream variability.

680 Figure S3. Winter EOFs of SLP, 1980-2014 from 20CR and ERA-I

681 Figure S4. Summer EOFs of SLP, 1979-2014 from 20CR and ERA-I

682

683

684

685

686

687

688

689 


\section{References}

692 Adler RF, Huffmann GJ, Chang A, Ferraro R, Xie P, Janowiak J, Rudolf B, Schneider S, Curtis S, 693 Bolvin D, Gruber A, Susskind J, Arkin P. 2003. The version 2 Global Precipitation Climatology 694 Project (GPCP) monthly precipitation analysis 1979-present. Journal of Hydrometeorology 4: $695 \quad 1147-1167$.

696 Alexander LV, Jones PD. 2001. Updated precipitation series for the U.K. and discussion of 697 recent extremes. Atmospheric Science Letters 1: 142-150. doi: 10.1006/asle.2001.0025.

698 Andrews MB, Knight JR, Gray LJ. 2015. A simulated lagged response of the North Atlantic 699 Oscillation to the solar cycle over the period 1960-2009. Environmental Research Letters 10: 700 054022. doi: 10.1088/1748-9326/10/5/054022.

701 Barnston AG, Livezey RE. 1987. Classification, seasonality and persistence of low-frequency 702 atmospheric circulation patterns. Monthly Weather Review 115:1083-1126.

703 Bell VA, Davies HN, Kay AL, Brookshaw A, Scaife AA. 2017. A national-scale seasonal

704 hydrological forecast system: development and evaluation over Britain. Hydrological and

705 Earth System Sciences Discussions doi: 10.5194/hess-2017-154.

706 Benjamini Y, Hochberg Y. 1995. Controlling the false discovery rate: a practical and powerful 707 approach to multiple testing. Journal of the Royal Statistical Society B57: 289-300.

708 Blackburn M, Methven J, Roberts N. 2008. Large-scale context for the UK floods in summer 709 2007. Weather 63(9): 280-288, DOI:10.1002/wea.322.

710 Blanchard-Wrigglesworth E, Armour KC, Bitz CM. 2011. Persistence and inherent

711 predictability of Arctic sea ice in a GCM ensemble and observations. Journal of Climate 24: 
231-250, DOI: 10.1175/2010JCLI3775.1.

713 Brayshaw DJ, Hoskins B, Blackburn M. 2009. The basic ingredients of the North Atlantic

714 storm track. Part I: land-sea contrast and orography, Journal of the Atmospheric Sciences 66:

$715 \quad 2539-2558$.

716 Burningham $\mathrm{H}$, French J. 2013. Is the NAO winter index a reliable proxy for wind climate and

717 storminess in northwest Europe? International Journal of Climatology 33: 2036-2049. doi:

718 10.1002/joc.3571.

719 Clark RT, Bett PE, Thornton HE, Scaife AA. 2017. Skilful seasonal predictions for the

720 European energy industry. Environmental Research Letters 12: 024002. doi: 10.1088/1748-

721 9326/aa57ab.

722 Colantuano G, Wang Y, Hanna E, Erdélyi R. 2014. Signature of the North Atlantic Oscillation

723 on British solar radiation availability and PV potential: the winter zonal seesaw. Solar Energy

724 107: 210-219. doi: 10.1016/j.solener.2014.05.045.

725 Comas-Bru L, McDermott F. 2014. Impact of the EA and SCA patterns on the European

726 twentieth century NAO-winter climate relationship. Quarterly Journal of the Royal

727 Meteorological Society 140: 354-363. doi: 10.1002/qj.2158.

728 Compo GP, Whitaker JS, Sardeshmukh PD, Matsui N, Allan RJ, Yin X, Gleason Jr BE, Vose RS,

729 Rutledge G, Bessemoulin P, Brönnimann S, Brunet M, Crouthamel RI, Grant AN, Groisman

730 PY, Jones PD, Kruk MC, Kruger AC, Marshall GJ, Maugeri M, Mok HY, Nordli $\varnothing$, Ross TF, Trigo

731 RM, Wang XL, Woodruff SD, Worley SJ. 2011. The Twentieth Century Reanalysis Project.

732 Quarterly Journal of the Royal Meteorological Society 137: 1-28, DOI: 10.1002/qj.776.

733 Cropper T, Hanna E, Valente MA, Jónsson T. 2015. A daily Azores-Iceland North Atlantic 
734 Oscillation index back to 1850. Geoscience Data Journal 2(1): 12-24, DOI: 10.1002/gdj3.23

735 Czaja A, Marshall J. 2001. Observations of atmosphere-ocean coupling in the North Atlantic.

736 Quarterly Journal of the Royal Meteorological Society 127: 1893-1916.

737 Dee DP, Uppala SM, Simmons AJ, Berrisford P, Poli P, Kobayashi S, Andrae U, Balmaseda

738 MA, Balsamo G, Bauer P, Bechtold P, Beljaars ACM, van de Berg L, Bidlot J, Bormann N,

739 Delsol C, Dragani R, Fuentes M, Geer AJ, Haimberger L, Healy SB, Hersbach H, Hólm EV,

740 Isaksen L, Kållberg P, Köhler M, Matricardi M, McNally AP, Monge-Sanz BM, Morcrette J-J,

741 Park B-k, Peubey C, de Rosnay P, Tavolato C, Thépaut J-N, Vitart F. 2011. The ERA-Interim

742 reanalysis: configuration and performance of the data assimilation system. Quarterly

743 Journal of the Royal Meteorological Society 137: 553-597, DOI: 10.1002/qj.828

744 Dong B, Sutton RT, Woollings T, Hodges K. 2013a. Variability of the North Atlantic summer

745 storm track: mechanisms and impacts on European climate. Environmental Research Letters

746 8: 034037. doi: 10.1088/1748-9326/8/3/034037.

747 Dong B, Sutton RT, Woollings T. 2013b. The extreme European summer 2012. (In “Explaining

748 extreme events of 2012 from a climate perspective"). Bulletin of the American

749 Meteorological Society 94(9): S28-S32.

750 Duchon CE. 1979. Lanczos filtering in one and two dimensions. Journal of Applied

751 Meteorology 18: 1016-1022.

752 Dunstone N, Smith D, Scaife A, Hermanson L, Eade R, Robinson N, Andrews M, Knight J.

753 2016. Skilful predictions of the winter North Atlantic Oscillation one year ahead. Nature

754 Geoscience 9: 809-814. doi: 10.1038/NGEO2824 
755 Ely CR, Brayshaw DJ, Methven J, Cox J, Pearce O. 2013. Implications of the North Atlantic

756 Oscillation for a UK-Norway renewable power system. Energy Policy 62: 1420-1427. doi:

757 10.1016/j.enpol.2013.06.037.

758 Enfield DB, Mestas-Nuñez AM, Trimble PJ. 2001. The Atlantic multidecadal oscillation and its

759 relation to rainfall and river flows in the continental U.S. Geophysical Research Letters

760 28(10): 2077-2080

761 Feldstein S. 2000. The timescale, power spectra, and climate noise properties of

762 teleconnection patterns. Journal of Climate 13: 4430-4440.

763 Folland CK, Knight J, Linderholm HW, Fereday D, Ineson S, Hurrell JW. 2009. The Summer

764 North Atlantic Oscillation: past, present and future. Journal of Climate 22: 1082- 1103, doi:

$765 \quad 10.1175 / 2008 J C L I 2459.1$

766 Folland CK, Scaife AA, Lindesay J, Stephenson DB. 2012. How predictable is northern

767 European winter climate a season ahead? International Journal of Climatology 32: 801-818, 768 doi: 10.1002/joc.2314.

769 Gray LJ, Scaife AA, Mitchell DM, Osprey S, Ineson S, Hardiman S, Butchart N, Knight J, Sutton

770 R, Kodera K. 2013. A lagged response to the 11 year solar cycle in observed winter

771 Atlantic/European weather patterns. Journal of Geophysical Research: Atmospheres 118: 13

772 405-13-420, doi: 10.1002/2013JD020062.

773 Hall R, Erdélyi R, Hanna E, Jones JM, Scaife AA. 2015. Drivers of North Atlantic polar front jet

774 stream variability. International Journal of Climatology 35: 1697-1720. doi:

$77510.1002 /$ joc.4121. 
776 Hall RJ, 2016. The North Atlantic polar front jet stream: variability and predictability, 1871-

777 2014. Unpublished PhD thesis, University of Sheffield.

778 Hall RJ, Scaife AA, Hanna E, Jones JM, Erdélyi R. 2017a. Simple statistical probabilistic

779 forecasts of the winter NAO. Weather and Forecasting 32: 1585-1601. doi: 10.1175/WAF-D-

$780 \quad 16-0124 . S 1$.

781 Hall RJ, Jones JM, Hanna E, Scaife AA, Erdélyi R. 2017b. Drivers and potential predictability of

782 summer North Atlantic polar front jet variability. Climate Dynamics 48: 3869-3887. doi:

$783 \quad 10.1007 / \mathrm{s} 00382-016-3307-0$

784 Hanna E, Cropper TE. 2017. North Atlantic Oscillation. Oxford Research Encyclopedia of

785 Climate Science. doi: 10.1093/acrefore/9780190228620.013.22

786 Hertig E, Beck C, Wanner H, Jacobeit J. 2015. A review of non-stationarities in climate

787 variability of the last century with a focus on the North Atlantic-European sector. Earth

788 Science Reviews 147: 1-17. doi: 10.1016/j.earscirev.2015.04.009.

789 Hulme M, Barrow E, (eds). 1997. Climates of the British Isles: present, past and future.

790 Routledge, London.

791 Huntingford C, Marsh T, Scaife AA, Kendon EJ, Hannaford J, Kay AL, Lockwood M,

792 Prudhomme C, Reynard NS, Parry S, Lowe JA, Screen JA, Ward HC, Roberts M, Stott PA, Bell

793 VA, Bailey M, Jenkins A, Legg T, Otto FEL, Massey N, Schaller N, Slingo J, Allen MR. 2014.

794 Potential influences on the United Kingdom's floods of winter 2013/14. Nature Climate

795 Change 4: 769-777. doi: 10.1038/NCLIMATE2314.

796 Hurrell JW. 1995. Decadal trends in the North Atlantic Oscillation and relationships to

797 regional temperature and precipitation. Science 269: 676-679.

798 Hurrell JW, Kushnir Y, Visbeck M, Ottersen G. 2003. An overview odf the North Atlantic 
799 Oscillation. In Hurrell JW, Kushnir Y, Ottersen G, Visbeck M, (eds). The North Atlantic

800 Oscllation, Climatic Significance and Environmental Impact. AGU Geophysical Monograph

$801 \quad 134$, pp1-35.

802 Hurrell JW, Deser C. 2009. North Atlantic climate variability: the role of the North Atlantic

803 Oscillation. Journal of Marine Systems 78: 228-41. doi: 10.1016/j.jmarsys.2008.11.026.

804 James IN, James PM. 1989. Ultra-low-frequency variability in a simple atmospheric

805 circulation mode. Nature 342: 53-55.

806 Jones PD, Jónsson T, Wheeler D. 1997. Extension to the North Atlantic Oscillation using early

807 instrumental pressure observations from Gibraltar and south-west Iceland. International

808 Journal of Climatology 17: 1433-1450.

809 Kalnay E, Kanamitsu M, Kistler R, Collins W, Deavon D, Gandin L, Iredell M, Saha S, White G,

810 Woollen J, Zhu Y, Chelliah M, Ebisuzaki W, Higgins W, Janowiak J, Mo KC, Ropelewski C,

811 Wang J, Leetmaa A, Reynolds R, Jenne R, Joseph D. 1996. The NCEP/NCAR 40-year reanalysis

812 project. Bulletin of the American Meteorological Society 77: 437-471.

813 Kaplan A, Cane M, Kushnir Y, Clement A, Blumenthal M, Rajagopalan B. 1998. Analyses of

814 global sea surface temperature 1856-1991, Journal of Geophysical Research 103: 18567-

81518589.

816 Lim YK. 2015. The East Atlantic / West Russia teleconnection in the North Atlantic: climate

817 impact and relation to Rossby wave propagation. Climate Dynamics 44: 3211-3222. doi:

$818 \quad 10.1007 / \mathrm{s} 00382-014-2381-4$

819 Manley G. 1953. The mean temperature of Central England, 1698-1952. Quarterly journal of

820 the Royal Meteorological Society 79: 242-261. 
821 Moore GWK, Renfrew IA. 2012. Cold European winters: interplay between the NAO and the

822 East Atlantic mode. Atmospheric Science Letters 13: 1-8. doi: 10.1002/asl.356.

823 Naujokat B. 1986. An update of the observed quasi-biennial oscillation of the stratospheric

824 winds over the tropics. Journal of the Atmospheric Sciences 43: 1873-1877.

825 North GR, Bell TL, Cahalan RF, Moenig FJ. 1982. Sampling errors in the estimation of

826 empirical orthogonal functions Monthly Weather Review 110: 669-706.

827 O'Reilly C, Woollings T, Zanna L. 2017. The dynamical influence of the Atlantic Multidecadal

828 Oscillation on continental climate. Journal of Climate. doi: 10.1175/JCLI-D-16-0345.1, in

829 press.

830 Palin EJ, Scaife AA, Wallace E, Pope ECD, Arribas A, Brookshaw A. 2016. Skillful seasonal

831 forecasts of winter disruption to the U.K. transport system. Journal of Applied Meteorology

832 and Climatology 55: 325-344. doi: 10.1175/JAMC-D-15-0102.1.

833 Parker DE, Legg TP, Folland CK. 2003. A new daily central England temperature series, 1772-

834 1991. International Journal of Climatology 12: 317-342.

835 Perry M, Hollis D. 2005. The development of a new set of long-term climate averages for the

836 UK. International Journal of Climatology 25: 1023-1039. doi: 10.1002/joc.1160.

837 Rayner NA, Parker DE, Horton EB, Folland CK, Alexander LV, Rowell DP, Kent EC, Kaplan A.

838 2003. Global analyses of sea surface temperature, sea ice, and night marine air temperature

839 since the late nineteenth century. Journal of Geophysical Research: Atmospheres 108(D14):

840 4407. doi: 10.1029/2002JD002670.

841 Robinson DA, Estilow TW, NOAA CDR program 2012. Accessed $5^{\text {th }}$ March 2017. NOAA

842 Climate Data Record (CDR) of Northern Hemisphere (NH) Snowcover extent (SCE), v01r01.

843 NOAA National Climatic Data Center. doi: 10.7289/V5N014G9. 
844 Scaife AA, Ineson S, Knight JR, Gray L, Kodera K, Smith DM. 2013. A mechanism for lagged

845 North Atlantic climate response to solar variability. Geophysical Research Letters 40(2): 434-

846 439. doi: $10.1002 / g r l .50099$.

847 Scaife AA, Arribas A, Blockley E, Brookshaw A, Clark RT, Dunstone N, Eade R, Fereday D,

848 Folland CK, Gordon M, Hermanson L, Knight JR, Lea DJ, MacLachlan C, Maidens A, Martin M,

849 Peterson AK, Smith D, Vellinga M, Wallace E, Waters J, Williams A. 2014a. Skillful long-range

850 prediction of European and North American winters. Geophysical Research Letters 41: 2514-

851 2519. doi: 10.1002/2014GL059637.

852 Seierstad IA, Stephenson DB, Kvamst $\varnothing$ NG. 2007. How useful are teleconnection patterns

853 for explaining variability in extratropical storminess? Tellus 59A: 170-181. doi:

$854 \quad 10.1111 /$ j.1600-0870.2007.00226.x.

855 Smith DM, Scaife AA, Eade R, Knight JR. 2016. Seasonal to decadal prediction of the winter

856 North Atlantic Oscillation: emerging capability and future prospects. Quarterly Journal of the

857 Royal Meteorological Society 142: 611-617. doi: 10.1002/qj.2479.

858 Stockdale TN, Molteni F, Ferranti L. 2015. Atmospheric initial conditions and the

859 predictability of the Arctic Oscillation. Geophysical Research Letters 42: 1173-1179. doi:

$86010.1002 / 2014 G L 062681$.

861 Sutton RT, Dong B. 2012. Atlantic Ocean influence on a shift in European climate in the 862 1990s. Nature Geoscience 5: 788-792. doi: 10.1038/ngeo1595.

863 Svensson C, Brookshaw A, Scaife AA, Bell VA, Mackay JD, Jackson CR, Hannaford J, Davies

$864 \mathrm{HN}$, Arribas A, Stanley S. 2015. Long-range forecasts of UK winter hydrology. Environmental

865 Research Letters 10: 064006. doi: 10.1088/1748-9326/10/6/064006. 
866 Thornton HE, Scaife AA, Hoskins BJ, Brayshaw DJ. 2017. The relationship between wind

867 power, electricity demand and winter weather patterns in Great Britain. Environmental

868 Research Letters 12: 064017. doi: 10.1088/1748-9326/aa69c6.

869 Vallis GK, Gerber EP. 2008. Local and hemispheric dynamics of the North Atlantic Oscillation,

870 annular patterns and the zonal index. Dynamics of Oceans and Atmospheres 44: 184-212.

871 doi: 10.1016/j.dynatmoce.2007.04.003.

872 Van Oldenborgh GJ, Stephenson DB, Sterl A, Vautard R, Yiou P, Drijfhout SS, von Storch H,

873 van den Dool H. 2015. Drivers of the 2013/14 winter floods in the UK. Nature Climate

874 Change 5: 490-491.

875 Wallace JM, Gutzler DS. 1981. Teleconnections in the geopotential height field during the

876 northern hemisphere winter. Monthly Weather Review 109: 784-812.

877 Wang L, Ting M, Kushner P. 2017. A robust empirical seasonal prediction of winter NAO and

878 surface climate. Scientific Reports 7: 279. doi: 10.1038/s41598-017-00353-y.

879 Wanner H, Brönnimann S, Casdty C, Gyalistras D, Luterbacher J, Schmutz C, Stephenson DB,

880 Xoplaki E. 2001. North Atlantic Oscillation-concepts and studies. Surveys in Geophysics 22:

$881 \quad 321-382$.

882 Wigley TML, Lough JM, Jones PD. 1984. Spatial patterns of precipitation in England and

883 Wales and a revised, homogenous England and Wales precipitation series. Journal of

884 Climatology 4: 1-25.

885 Wilks DS. 2011. Statistical Methods for the Atmospheric Sciences, third edition. Academic 886 Press, New York.

887 Wood NLH. 2004. Regional climate trends in south-west England and the North Atlantic

888 Oscillation. Weather 59: 39-41. doi: 10.1256/wea.28.03. 
889 Woollings T. 2010. Dynamical influences on European climate: an uncertain future.

890 Philosophical Transactions of the Royal Society of London A: mathematical, physical

891 and engineering sciences 368: 3722-3756. doi: 10.1098/rsta.2010.0040.

892 Woollings T, Blackburn M. 2012. The North Atlantic jet stream under climate change and its

893 relation to the NAO and EA patterns. Journal of Climate 25: 886-902. doi: 10.1175/JCLI-D-11-

89400087.1.

895 Woollings T, Hannachi A, Hoskins B. 2010b. Variability of the North Atlantic eddy-driven jet

896 stream, Quarterly Journal of the Royal Meteorological Society 136: 856-868. doi:

897 10.1002/qj.625.

898 Woollings T, Czuchnicki C, Franzke C. 2014. Twentieth century North Atlantic jet variability.

899 Quarterly Journal of the Royal Meteorological Society 140: 783-791. doi: 10.1002/qj.2197.

900 Zubiate L, McDermott F, Sweeney C, O’Malley M. 2016. Spatial variability in winter NAO-

901 wind relationships in western Europe linked to concomitant states of the East Atlantic and

902 Scandinavian patterns. Quarterly Journal of the Royal Meteorological Society 143: 552-562.

903 doi: 10.1002/qj.2943.

904

905

906

907

908

909

910

911 
912 Figure Captions.

913

914 Figure 1. Rainfall anomaly maps for winter a) 2013-14, b) 2014-15 and c) 2015-16 relative to

915 1981-2010 climatology. The Hurrell PC NAO indices for the three winters are 0.59, 1.67 and

9160.95 respectively. (CPC indices are: NAO: 0.56, 1.42, 0.99; EA: 0.57, 0.16, 2.00; SCA: 0.71, -

$9170.32,-0.38)$. Figures from the UK Met Office.

918

919 Figure 2. differences between winter $2013 / 14$ and $2014 / 15$ for a) zonal windspeed at

$920850 \mathrm{hPa}$ and b) SLP. Data from NCEP/NCAR reanalysis. Contours are shown for the major

921 tickmarks, with negative contours dotted.

922 Figure 3. First 3 EOFs of SLP for a) winter and b) summer derived from 20CRv2, 1951-2014.

923 The percentage of SLP variance explained by each EOF is indicated.

924 Figure 4. Correlations of DJF mean temperature with metrics of Atlantic atmospheric

925 circulation, 1952-2011. Black contours denote correlations significant at $p \leq 0.05$. Data from

926 UKCP09 5km gridded data.

927 Figure 5. As for Figure 4 except for JJA mean temperature, 1951-2011.

928 Figure 6. As for Figure 4 except for DJF total precipitation, 1952-2011. Note that blue shows

929 a positive correlation.

930 Figure 7. As for Figure 4, except for JJA total precipitation, 1951-2011. Note that blue shows

931 a positive correlation.

932 Figure 8. Composites of $850 \mathrm{hPa}$ vector wind and $925 \mathrm{hPa}$ air temperature anomalies, for

933 each of the DJF circulation indices. Figures derived from composites of the ten highest 
934 minus the 10 lowest years of the index in question, from 1951-2014. Taken from

935 NCEP/NCAR reanalysis.

936 Figure 9. As for Figure 8, except for JJA. 

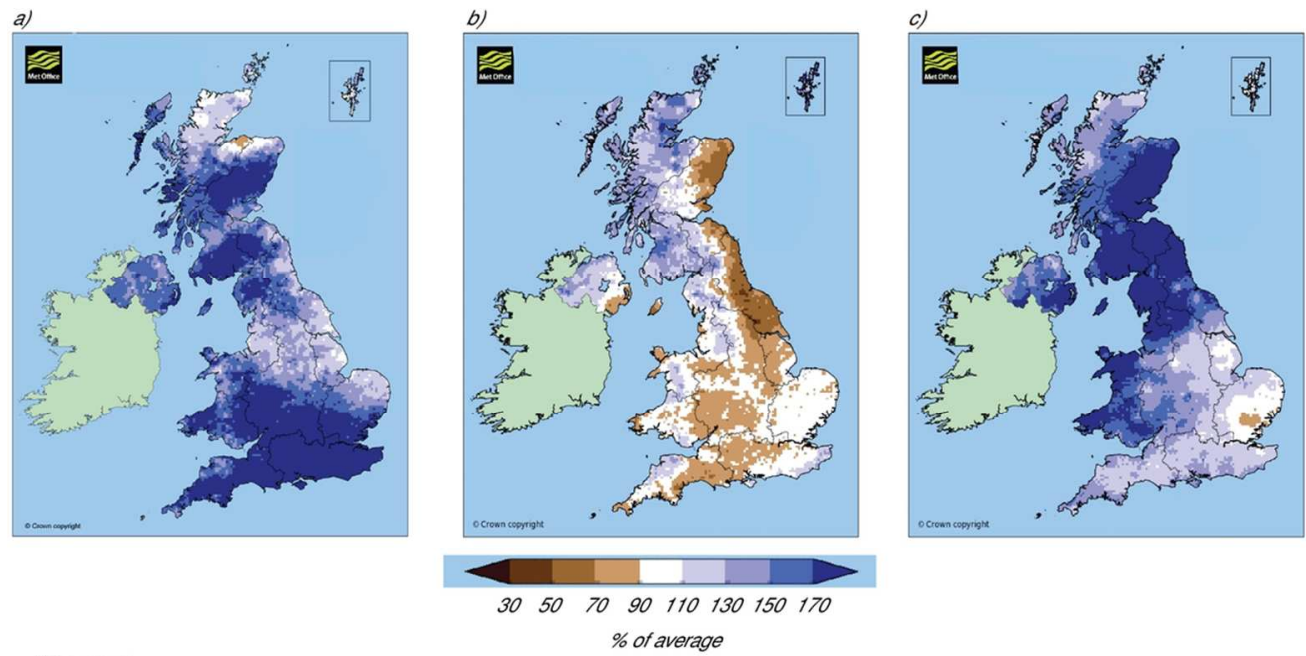

Figure 1

Figure 1. Rainfall anomaly maps for winter a) 2013-14, b) 2014-15 and c) 2015-16 relative to 1981-2010 climatology. The Hurrell PC NAO indices for the three winters are $0.59,1.67$ and 0.95 respectively. (CPC indices are: NAO: $0.56,1.42,0.99$; EA: $0.57,0.16,2.00 ;$ SCA: $0.71,-0.32,-0.38$. )

$101 \times 52 \mathrm{~mm}(300 \times 300$ DPI $)$ 

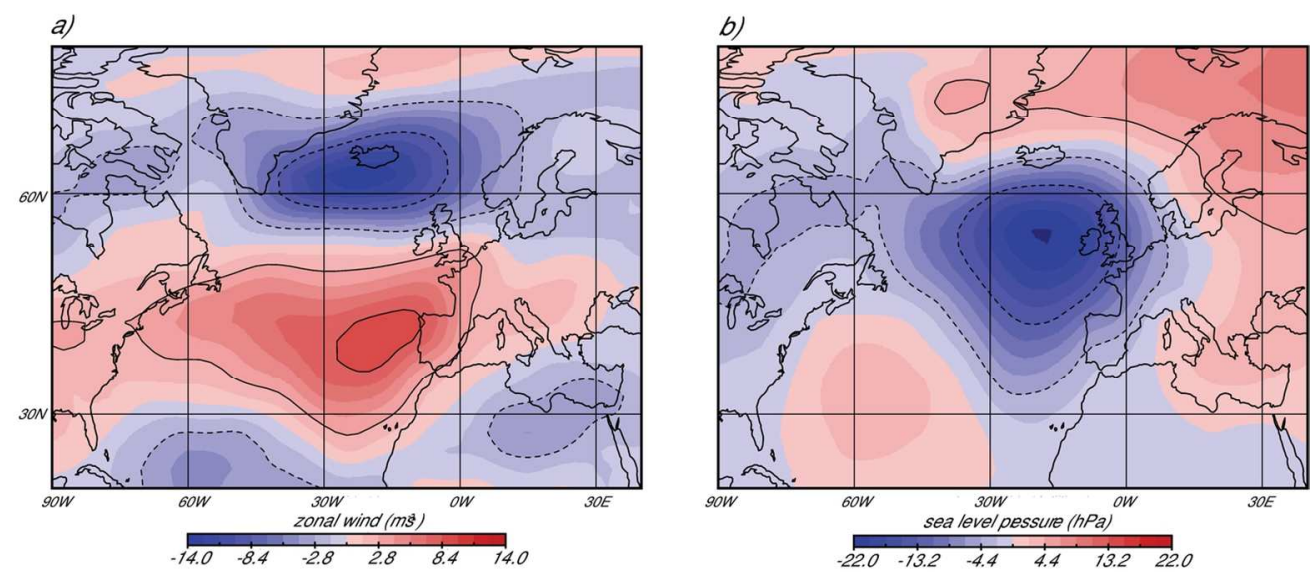

Figure 2

Figure 2. differences between winter 2013/14 and 2014/15 for a) zonal windspeed at 850hPa and b) SLP. Data from NCEP/NCAR reanalysis. Contours are shown for the major tickmarks, with negative contours dotted.

$127 \times 64 \mathrm{~mm}(300 \times 300$ DPI $)$ 

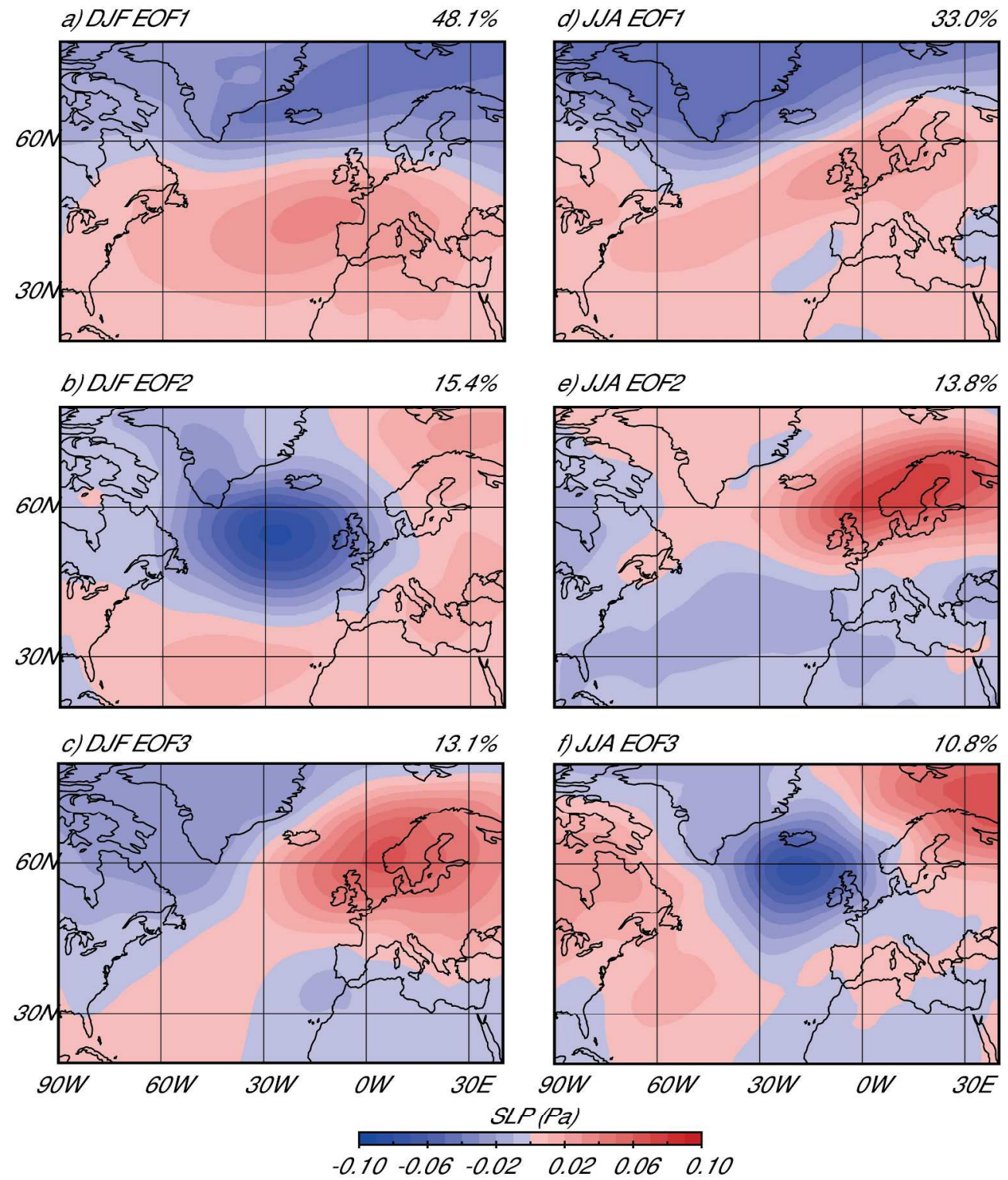

Figure 3

Figure 3. First 3 EOFs of SLP for a) winter and b) summer derived from 20CRv2, 1951-2014. The percentage of SLP variance explained by each EOF is indicated.

$255 \times 310 \mathrm{~mm}(300 \times 300 \mathrm{DPI})$ 
a) $E A$

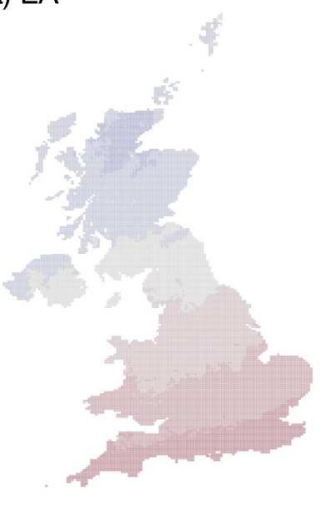

d) PC2

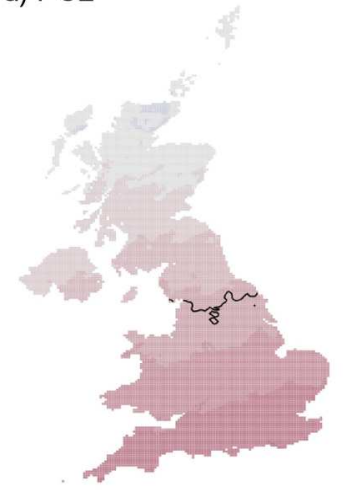

b) SCA

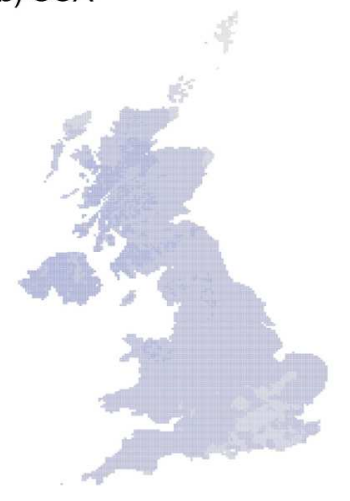

e) $\mathrm{PC} 3$

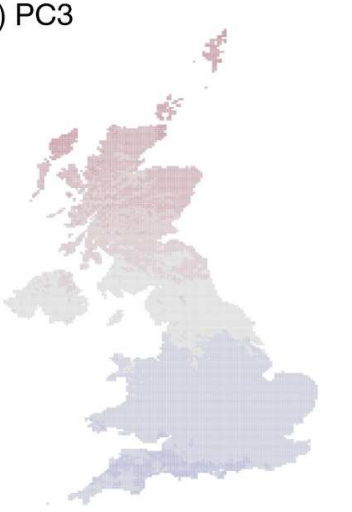

c) PC1

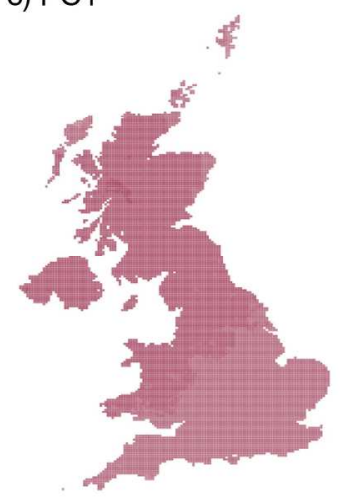

f) jet speed

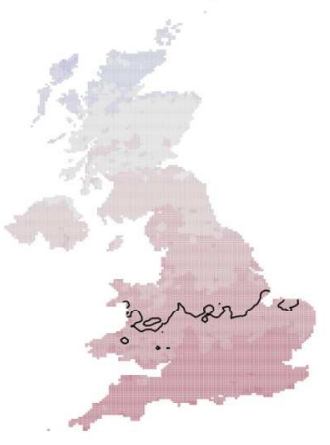

Figure 4

Figure 4. Correlations of DJF mean temperature with metrics of Atlantic atmospheric circulation, 1952-2011. Black contours denote correlations significant at $p \leq 0.05$. Data from UKCP09 $5 \mathrm{~km}$ gridded data.

$191 \times 203 \mathrm{~mm}(300 \times 300$ DPI $)$ 
a) $E A$

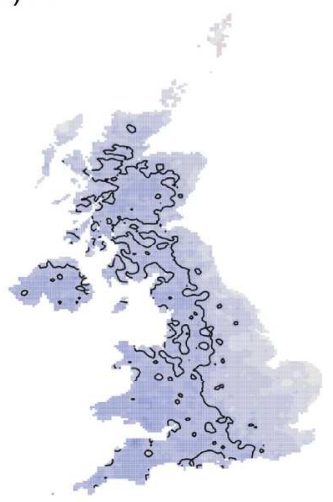

d) PC2

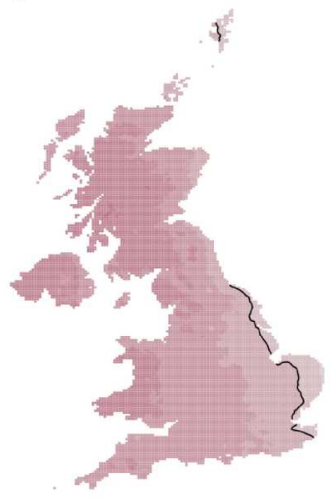

b) SCA

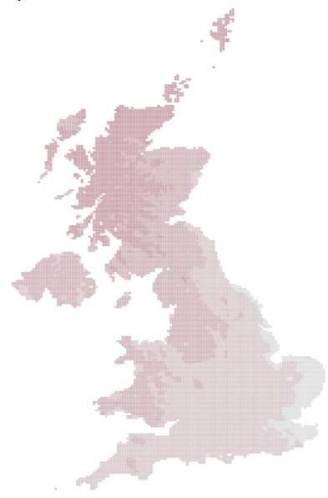

e) PC3

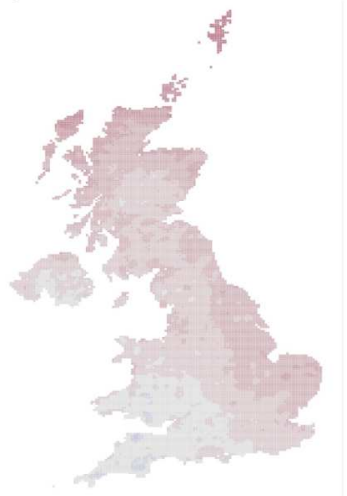

c) PC1

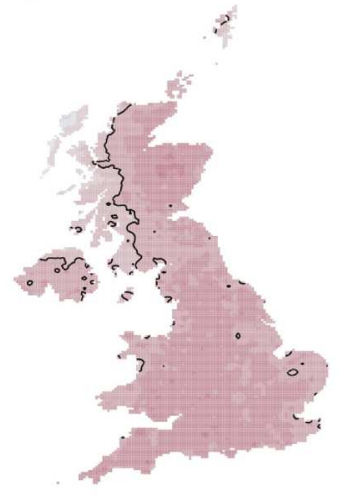

f) jet speed

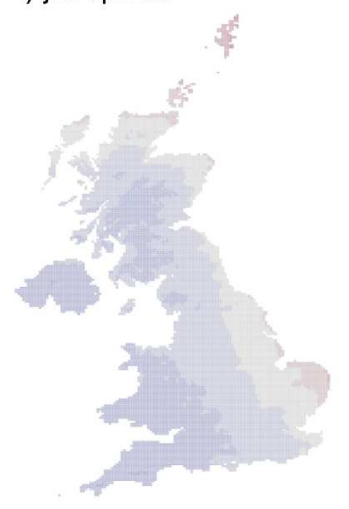

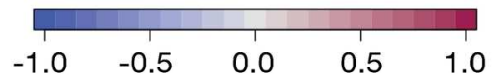

Figure 5

Figure 5. As for Figure 4 except for JJA mean temperature, 1951-2011.

$186 \times 195 \mathrm{~mm}(300 \times 300 \mathrm{DPI})$ 
a) EA

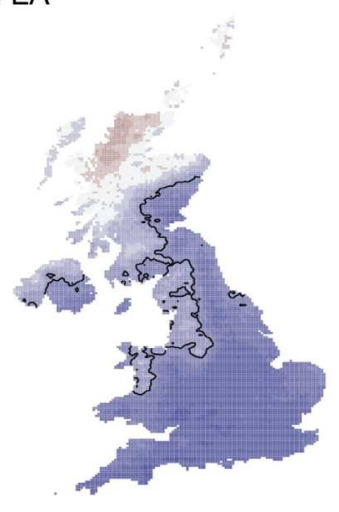

d) PC2

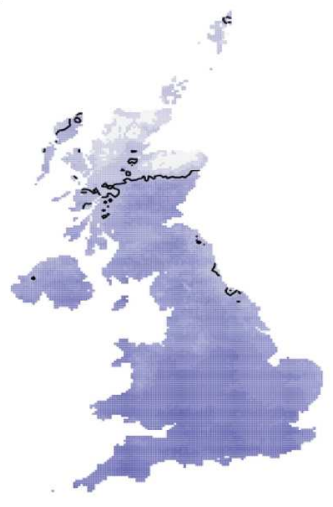

b) SCA

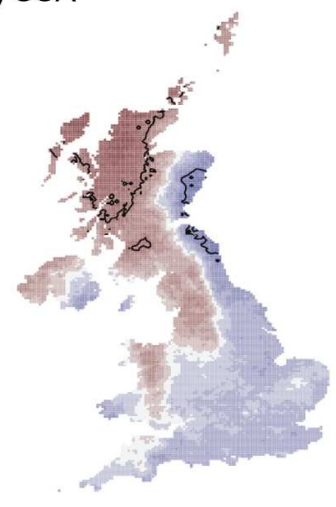

e) PC3

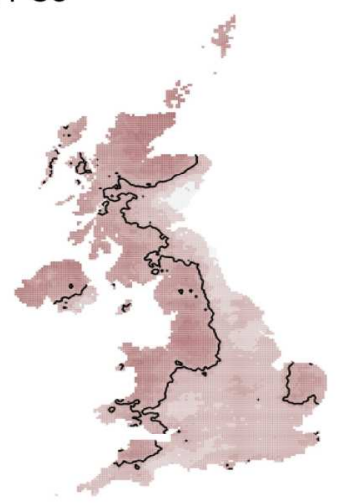

c) PC1

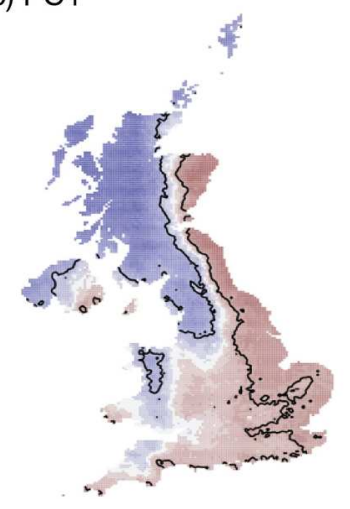

f) jet speed

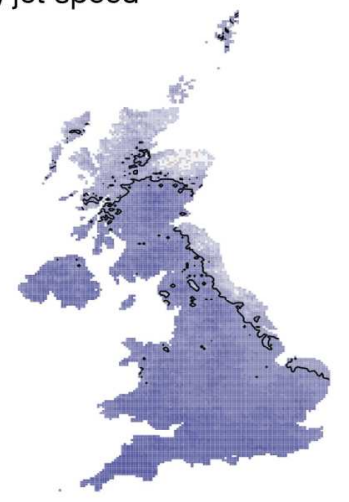

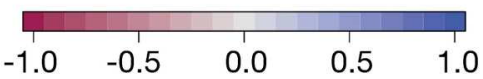

Figure 6

Figure 6. As for Figure 4 except for DJF total precipitation, 1952-2011. Note that blue shows a positive correlation.

$177 \times 176 \mathrm{~mm}(300 \times 300$ DPI $)$ 
a) EA

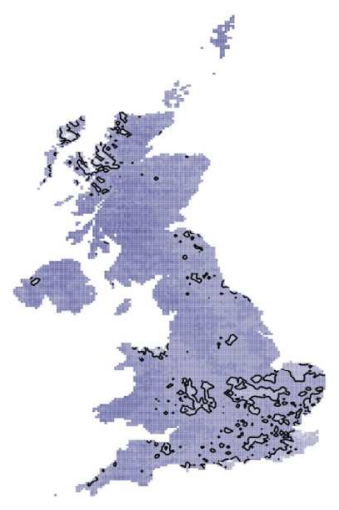

d) PC2

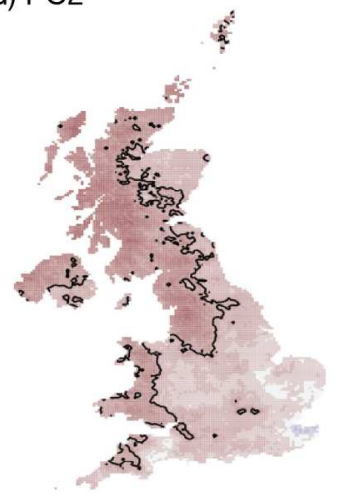

b) SCA

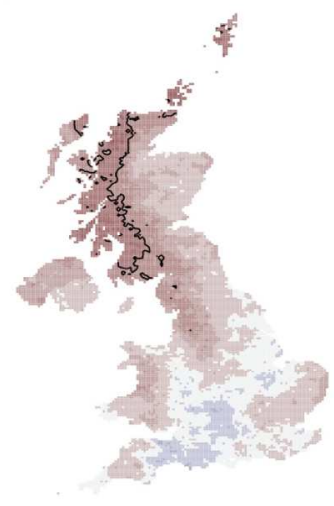

e) PC3

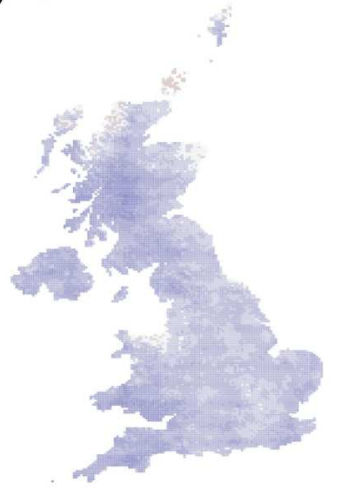

c) PC1

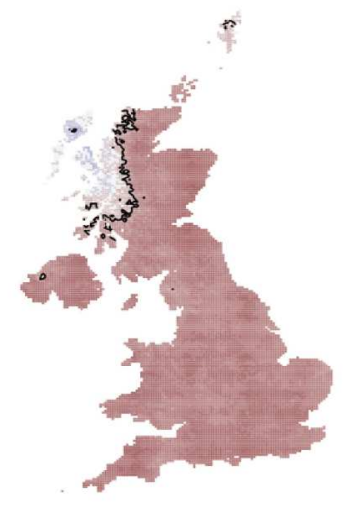

f) jet speed

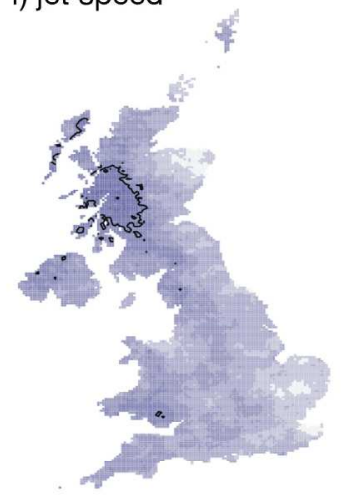

$\begin{array}{lllll}-1.0 & -0.5 & 0.0 & 0.5 & 1.0\end{array}$

\section{Figure 7}

Figure 7. As for Figure 4, except for JJA total precipitation, 1951-2011. Note that blue shows a positive correlation.

$185 \times 193 \mathrm{~mm}(300 \times 300 \mathrm{DPI})$ 

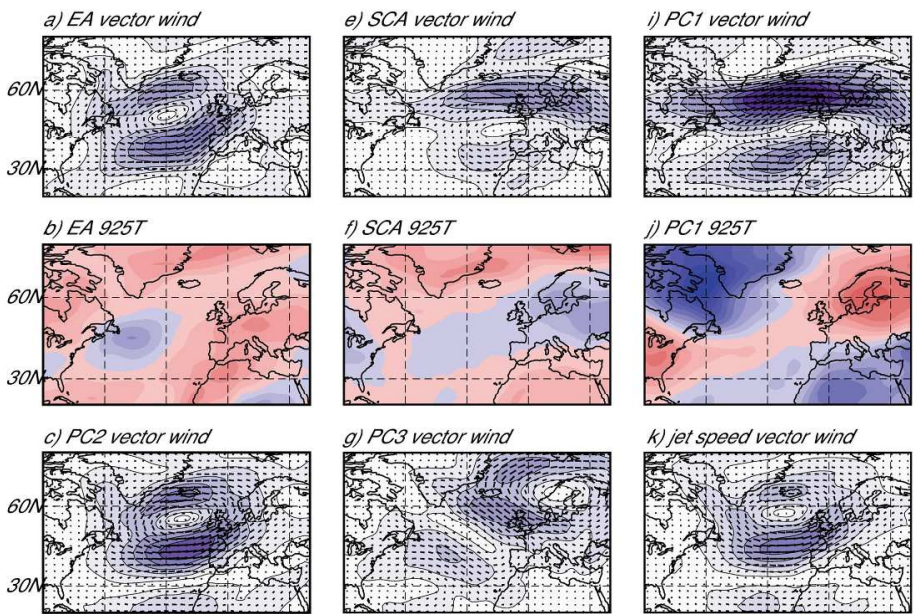

g) PC3 vector wind

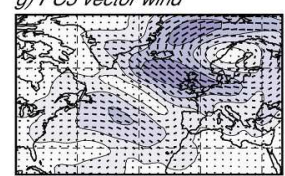

j) PC1 9251

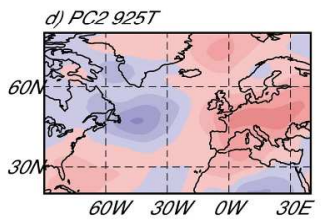

h) PC3 $925 T$
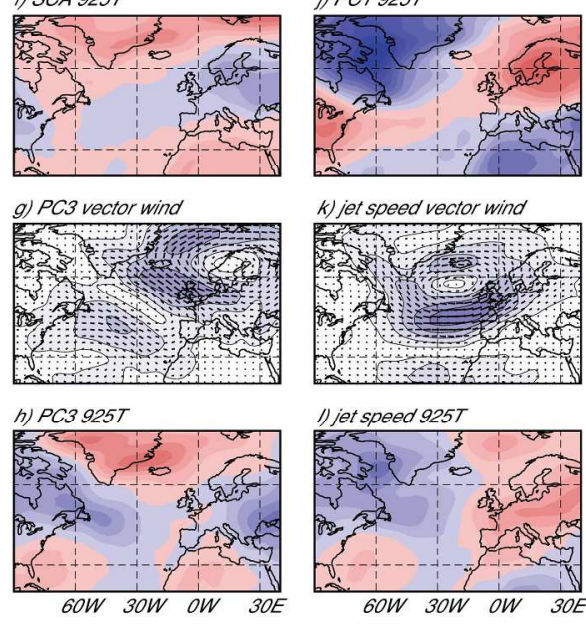

k) jet speed vector wind
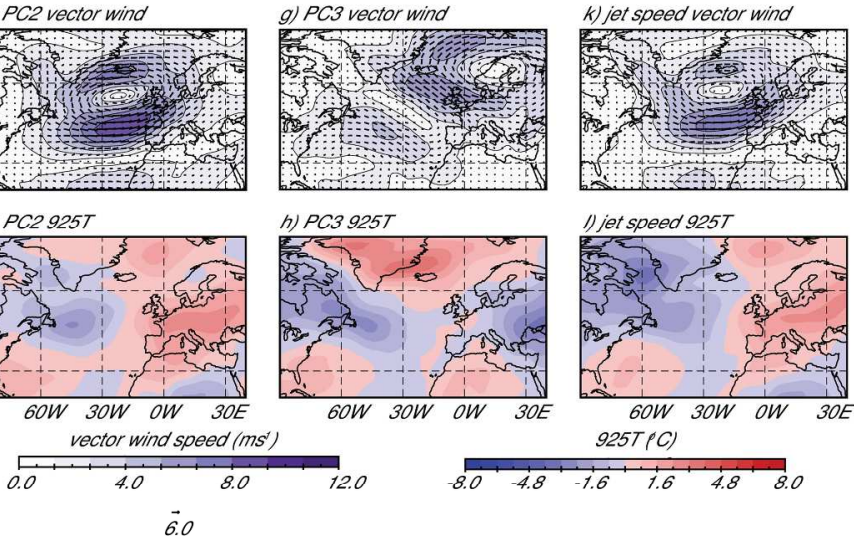

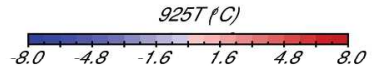

1) jet speed $925 \mathrm{~T}$

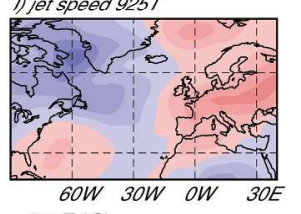

Figure 8

Figure 8. Composites of $850 \mathrm{hPa}$ vector wind and $925 \mathrm{hPa}$ air temperature anomalies, for each of the DJF circulation indices. Figures derived from composites of the ten highest minus the 10 lowest years of the index in question, from 1951-2014. Taken from NCEP/NCAR reanalysis.

$222 \times 175 \mathrm{~mm}(300 \times 300 \mathrm{DPI})$ 

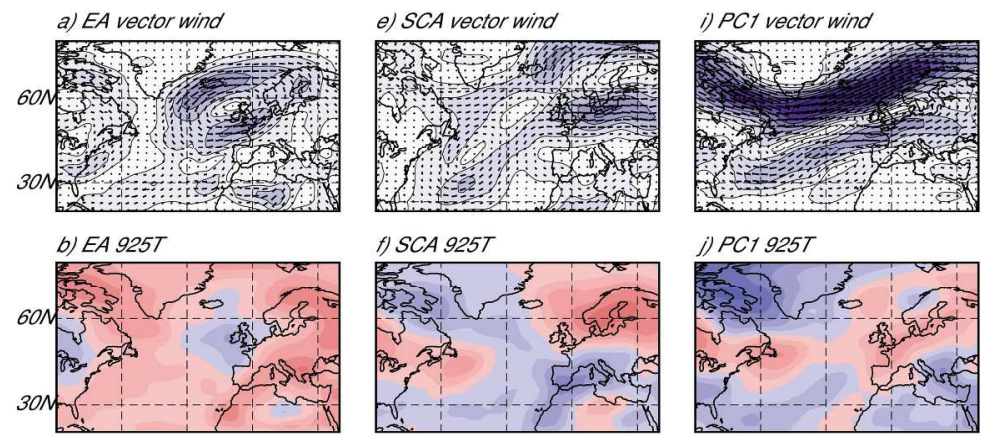

f) SCA $925 T$

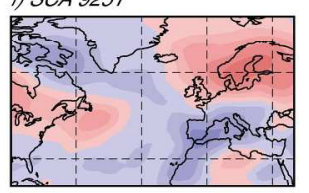

i) PC1 $925 \mathrm{~T}$
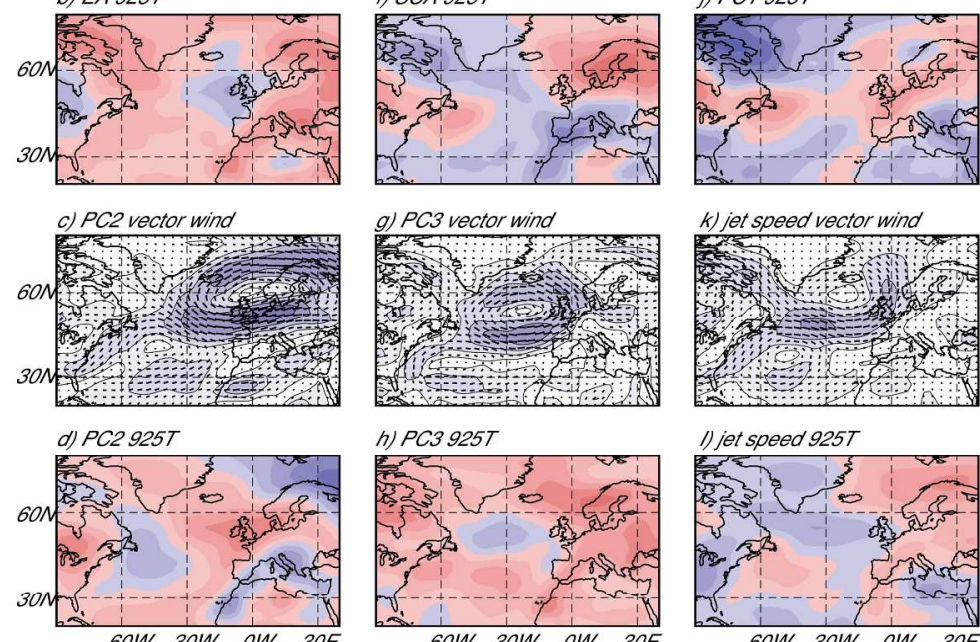

h) PC3 $925 T$
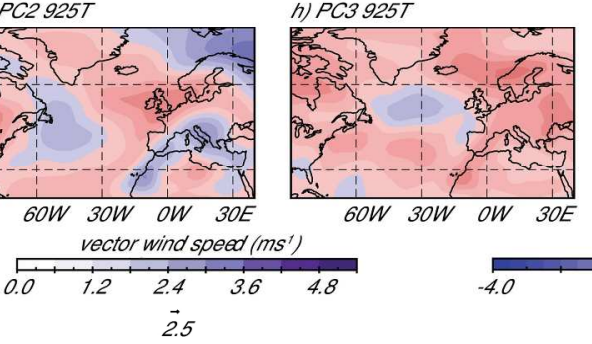

k) jet speed vector wind

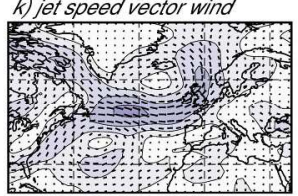

1) jet speed $925 T$

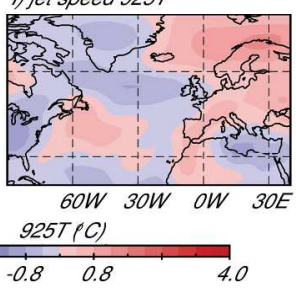

Figure 9

Figure 9. As for Figure 8, except for JJA.

$225 \times 191 \mathrm{~mm}(300 \times 300$ DPI $)$ 


\begin{tabular}{|c|c|c|c|}
\hline dataset & Variable used & Region selected & Dates used \\
\hline $\begin{array}{l}\text { NAO-CPC/EA- } \\
\text { CPC/SCA-CPC }\end{array}$ & 500hPha GPH & $\begin{array}{l}\text { Northern hemisphere, } 20- \\
90 \mathrm{~N}\end{array}$ & $1951-2016$ \\
\hline SNAO & SLP (NCEP/NCAR) & $90 \mathrm{~W}-30 \mathrm{E}, 40-70 \mathrm{~N}$ & 1951-2016 \\
\hline $\begin{array}{l}\text { Hurrell station } \\
\text { NAO }\end{array}$ & SLP & $90 W-40 E, 20-80 N$ & 1951-2016 \\
\hline CET & seasonal temperature & Central England & 1951-2016 \\
\hline HadUKP & Seasonal precipitation & UK regions & 1951-2016 \\
\hline UKCP09 & temperature, precipitation & $5 \mathrm{~km}$ grid over UK & 1951-2011 \\
\hline 20CRv2c & $\begin{array}{l}\text { zonal wind (jet speed and } \\
\text { latitude } \\
\text { SLP (EOFs) }\end{array}$ & $\begin{array}{l}60-0 \mathrm{~W}, 16-76 \mathrm{~N} \\
90 \mathrm{~W}-40 \mathrm{E}, 20-80 \mathrm{~N} \\
\end{array}$ & $\begin{array}{r}1951-2014 \\
1951-2014 \\
\end{array}$ \\
\hline ERA-I & $\begin{array}{l}\text { Zonal wind (jet speed and } \\
\text { latitude } \\
\text { SLP (EOFs) }\end{array}$ & $\begin{array}{l}60-0 \mathrm{~W}, 16-76 \mathrm{~N} \\
90 \mathrm{~W}-40 \mathrm{E}, 20-80 \mathrm{~N}\end{array}$ & $\begin{array}{l}1979-2016 \\
1979-2016 \\
\end{array}$ \\
\hline $\begin{array}{l}\text { NCEP-NCAR } \\
\text { reanalysis }\end{array}$ & $\begin{array}{l}\text { 850hPa Vector winds, } \\
\text { 925hpA temperature }\end{array}$ & $90 W-40 E, 20-80 N$ & 1951-2016 \\
\hline HadISST1 & $\begin{array}{l}\text { Sea ice concentration } \\
\text { SST (NA Tripole) } \\
\text { N3.4 }\end{array}$ & $\begin{array}{l}30-90 \mathrm{E}, 70-85 \mathrm{~N}(\mathrm{BKI}) \\
35-0 \mathrm{~W}, 80-90 \mathrm{~N}(\mathrm{GI}) \\
60-40 \mathrm{~W}, 40-55 \mathrm{~N} \text { minus } 80- \\
60 \mathrm{~W}, 25-35 \mathrm{~N} \\
120-170 \mathrm{~W}, 5 \mathrm{~N}-5 \mathrm{~S}\end{array}$ & $\begin{array}{r}1951-2016 \\
1951-2016 \\
1951-2016 \\
\end{array}$ \\
\hline snowcover & $\begin{array}{l}\text { Snowcover extent, Rutgers } \\
\text { University }\end{array}$ & $\begin{array}{l}55-150 \mathrm{E}, 45-80 \mathrm{~N} \text { (Eurasia) } \\
130-70 \mathrm{~W}, 40-70 \mathrm{~N})(\mathrm{N} . \\
\text { America) }\end{array}$ & $1979-2016$ \\
\hline AMO & Kaplan SST & 0-70N (N Atlantic) & 1951-2016 \\
\hline Solar variability & Sunspot numbers & NA & 1951-2016 \\
\hline QBO & 30hPa zonal winds & NA & 1951-2016 \\
\hline GPCPv2 & $\begin{array}{l}\text { Tropical Atlantic } \\
\text { precipitation }\end{array}$ & $10-35 W, 5 N-5 S$ & $1979-2016$ \\
\hline
\end{tabular}

Table 1. Summary of datasets used, the regions and time periods extracted. 


\begin{tabular}{|l|c|c|c|c|c|c|c|c|c|}
\hline a) DJF & $\begin{array}{c}\text { NAO- } \\
\text { CPC }\end{array}$ & EA & SCA & PC1 & PC2 & PC3 & $\begin{array}{c}\text { Jet } \\
\text { speed }\end{array}$ & $\begin{array}{c}\text { Jet } \\
\text { latitude }\end{array}$ & Hstat \\
\hline NAO-CPC & & -0.17 & $\mathbf{- 0 . 3 0}$ & $\mathbf{0 . 8 9}$ & 0.11 & -0.14 & $\mathbf{0 . 2 8}$ & $\mathbf{0 . 7 7}$ & $\mathbf{0 . 9 4}$ \\
\hline EA & -0.15 & & 0.07 & -0.20 & $\mathbf{0 . 8 2}$ & 0.13 & $\mathbf{0 . 5 3}$ & $\mathbf{- 0 . 5 7}$ & -0.16 \\
\hline SCA & $-\mathbf{0 . 5 0}$ & -0.02 & & $\mathbf{- 0 . 4 6}$ & -0.02 & $\mathbf{0 . 3 5}$ & -0.09 & $\mathbf{- 0 . 2 9}$ & $\mathbf{- 0 . 2 8}$ \\
\hline PC1 & $\mathbf{0 . 9 0}$ & -0.21 & $-\mathbf{0 . 6 7}$ & & 0.004 & -0.05 & 0.18 & $\mathbf{0 . 8 2}$ & $\mathbf{0 . 8 9}$ \\
\hline PC2 & 0.16 & $\mathbf{0 . 8 2}$ & -0.19 & 0.04 & & -0.00 & $\mathbf{0 . 7 3}$ & $\mathbf{- 0 . 3 8}$ & 0.12 \\
\hline PC3 swap & -0.13 & 0.08 & 0.29 & -0.05 & 0.01 & & 0.07 & 0.07 & -0.07 \\
\hline Jet speed & $\mathbf{0 . 4 3}$ & $\mathbf{0 . 5 0}$ & -0.23 & 0.31 & $\mathbf{0 . 7 7}$ & -0.19 & & -0.07 & $\mathbf{0 . 3}$ \\
\hline Jet latitude & $\mathbf{0 . 7 1}$ & $-\mathbf{- 0 . 6 1}$ & $-\mathbf{0 . 3 7}$ & $\mathbf{0 . 7 9}$ & $-\mathbf{0 . 4 2}$ & -0.03 & -0.04 & & $\mathbf{0 . 7 9}$ \\
\hline Hstat & $\mathbf{0 . 9 2}$ & -0.10 & $-\mathbf{0 . 4 9}$ & $\mathbf{0 . 8 9}$ & 0.25 & 0.02 & $\mathbf{0 . 5 2}$ & $\mathbf{0 . 6 9}$ & \\
\hline
\end{tabular}

\begin{tabular}{|l|c|c|c|c|c|c|c|c|c|c|}
\hline b) JJA & $\begin{array}{c}\text { NAO- } \\
\text { CPC }\end{array}$ & EA & SCA & PC1 & PC2 & PC3 & SNAO & $\begin{array}{c}\text { Jet } \\
\text { speed }\end{array}$ & $\begin{array}{c}\text { Jet } \\
\text { latitude }\end{array}$ & Hstat \\
\hline NAO-CPC & & $\mathbf{- 0 . 2 5}$ & 0.21 & $\mathbf{0 . 9 0}$ & 0.00 & -0.01 & $\mathbf{0 . 8 1}$ & 0.12 & $\mathbf{0 . 7 1}$ & $\mathbf{0 . 4 7}$ \\
\hline EA & -0.05 & & -0.24 & -0.21 & $-\mathbf{0 . 3 8}$ & $\mathbf{0 . 3 7}$ & $\mathbf{- 0 . 4 4}$ & $\mathbf{0 . 3 6}$ & $-\mathbf{0 . 3 7}$ & $\mathbf{0 . 2 8}$ \\
\hline SCA & 0.22 & -0.22 & & 0.25 & $\mathbf{0 . 4 3}$ & 0.10 & $\mathbf{0 . 2 9}$ & -0.07 & 0.19 & 0.02 \\
\hline PC1 & $\mathbf{0 . 9 0}$ & -0.04 & 0.17 & & -0.04 & -0.03 & $\mathbf{0 . 8 5}$ & 0.10 & $\mathbf{0 . 7 4}$ & $\mathbf{0 . 5 3}$ \\
\hline PC2 & 0.10 & $\mathbf{0 . 3 8}$ & -0.04 & 0.04 & & 0.07 & $\mathbf{0 . 3 7}$ & $\mathbf{- 0 . 5 3}$ & 0.15 & $\mathbf{- 0 . 4 0}$ \\
\hline PC3 & 0.26 & 0.33 & 0.25 & 0.22 & -0.10 & & $\mathbf{0 . 3 0}$ & $\mathbf{0 . 5 9}$ & -0.24 & $\mathbf{0 . 2 8}$ \\
\hline SNAO & $\mathbf{0 . 8 0}$ & $-\mathbf{0 . 3 4}$ & 0.25 & $\mathbf{0 . 8 7}$ & -0.24 & -0.09 & & -0.24 & $\mathbf{0 . 7 6}$ & $\mathbf{0 . 2 7}$ \\
\hline Jet speed & 0.32 & $\mathbf{0 . 4 5}$ & -0.05 & 0.27 & $\mathbf{0 . 5 6}$ & $\mathbf{0 . 5 1}$ & -0.06 & & -0.13 & $\mathbf{0 . 5 0}$ \\
\hline Jet latitude & $\mathbf{0 . 6 4}$ & -0.30 & 0.09 & $\mathbf{0 . 6 8}$ & 0.33 & -0.13 & $\mathbf{0 . 7 3}$ & -0.09 & & $\mathbf{0 . 3 7}$ \\
\hline Hstat & $\mathbf{0 . 5 6}$ & 0.29 & 0.11 & $\mathbf{0 . 5 6}$ & $\mathbf{0 . 4 3}$ & 0.06 & $\mathbf{0 . 4 0}$ & $\mathbf{0 . 5 0}$ & $\mathbf{0 . 4 0}$ & \\
\hline
\end{tabular}

Table 2. Table of correlations between North Atlantic atmospheric circulation indices for a)

winter (DJF) and b) summer (JJA). Bold denotes correlation coefficients significant at $p \leq 0.05$.

Black figures above the diagonal denote correlations over 1951-2014, based on 20CRv2c SLP data for the PCs, while red figures are over the period 1979-2016 (JJA) and 1980-2016 (DJF), based on ERA-I SLP data for the PCs. NB for JJA, 1979+, PC2 is closer to EA and PC3 to SCA, whereas for 1950 this is reversed, explaining discrepancies in correlations (highlighted). 


\begin{tabular}{|l|l|l|l|l|l|l|l|l|l|l|l|l|}
\hline a) DJF & CET & EW & SEE & SWE & CE & NWE & NEE & S & SS & NS & ES & NI \\
\hline $\begin{array}{l}\text { NAO- } \\
\text { CPC }\end{array}$ & 0.63 & 0.09 & -0.07 & 0.19 & -0.14 & 0.48 & -0.08 & 0.69 & 0.71 & 0.77 & 0.20 & 0.41 \\
\hline EA & 0.16 & 0.63 & 0.60 & 0.64 & 0.6 & 0.34 & 0.60 & 0.24 & 0.24 & 0.09 & 0.37 & 0.31 \\
\hline SCA & -0.19 & 0.10 & 0.22 & 0.07 & 0.17 & -0.25 & 0.18 & -0.29 & -0.29 & -0.41 & 0.02 & -0.11 \\
\hline lat & 0.42 & -0.37 & -0.49 & -0.30 & -0.49 & 0.10 & -0.48 & 0.32 & 0.35 & 0.50 & -0.15 & 0.08 \\
\hline speed & 0.33 & 0.63 & 0.59 & 0.70 & 0.47 & 0.52 & 0.44 & 0.51 & 0.54 & 0.37 & 0.47 & 0.57 \\
\hline PC1 & 0.67 & -0.14 & -0.29 & -0.04 & -0.34 & 0.35 & -0.29 & 0.60 & 0.64 & 0.76 & 0.02 & 0.25 \\
\hline PC2 & 0.41 & 0.76 & 0.73 & 0.80 & 0.63 & 0.57 & 0.60 & 0.49 & 0.48 & 0.35 & 0.48 & 0.52 \\
\hline PC3 & -0.09 & -0.29 & -0.22 & -0.25 & -0.24 & -0.47 & -0.19 & -0.40 & -0.35 & -0.34 & -0.40 & -0.49 \\
\hline Hstat & 0.65 & 0.06 & -0.08 & 0.16 & -0.15 & 0.44 & -0.14 & 0.64 & 0.67 & 0.75 & 0.14 & 0.38 \\
\hline
\end{tabular}

\begin{tabular}{|l|l|l|l|l|l|l|l|l|l|l|l|l|}
\hline b)JJA & CET & EW & SEE & SWE & CE & NWE & NEE & S & SS & NS & ES & NI \\
\hline $\begin{array}{l}\text { NAO- } \\
\text { CPC }\end{array}$ & 0.44 & -0.65 & -0.59 & -0.6 & -0.58 & -0.61 & -0.63 & -0.52 & -0.51 & -0.17 & -0.60 & -0.59 \\
\hline EA & -0.33 & 0.40 & 0.31 & 0.41 & 0.34 & 0.45 & 0.35 & 0.50 & 0.51 & 0.44 & 0.39 & 0.47 \\
\hline SCA & 0.14 & -0.09 & -0.05 & -0.05 & -0.03 & -0.25 & -0.10 & -0.30 & -0.35 & -0.41 & -0.12 & -0.20 \\
\hline lat & 0.35 & -0.72 & -0.67 & -0.68 & -0.68 & -0.60 & -0.67 & -0.57 & -0.54 & -0.23 & -0.63 & -0.70 \\
\hline speed & -0.12 & 0.24 & 0.16 & 0.29 & 0.18 & 0.25 & 0.20 & 0.36 & 0.41 & 0.46 & 0.16 & 0.30 \\
\hline PC1 & 0.47 & -0.67 & -0.64 & -0.62 & -0.60 & -0.58 & -0.63 & -0.57 & -0.54 & -0.23 & -0.63 & -0.70 \\
\hline PC2 & 0.41 & -0.26 & -0.15 & -0.27 & -0.14 & -0.44 & -0.26 & -0.47 & -0.52 & -0.62 & -0.24 & -0.38 \\
\hline PC3 & 0.09 & 0.26 & 0.19 & 0.36 & 0.21 & 0.19 & 0.19 & 0.28 & 0.32 & 0.26 & 0.19 & 0.29 \\
\hline Hstat & 0.02 & -0.25 & -0.30 & -0.15 & -0.30 & -0.13 & -0.23 & -0.05 & 0.00 & 0.28 & -0.26 & -0.14 \\
\hline SNAO & 0.56 & -0.80 & -0.71 & -0.77 & -0.69 & -0.78 & -0.76 & -0.77 & -0.76 & -0.44 & -0.77 & -0.82 \\
\hline
\end{tabular}

Table 3. Correlations between detrended atmospheric circulation indices and detrended time series of temperature and precipitation for UK regions, 1951-2014 for a) winter (DJF) and b) summer (JJA). Dark (light) blue shows negative correlation significant at $p \leq 0.01$ (0.05). Dark (light) orange shows positive correlation significant at $p \leq 0.01(0.05)$. CET =

Central England temperature. Precipitation regions are: EW: England and Wales, SEE: Southeast England, SWE: south-west England, CEP: central England, NWE: north west England, NEE; north east England, S: Scotland, SS: southern Scotland, NS: Northern Scotland, ES: East Scotland, NI: Northern Ireland. 


\begin{tabular}{|l|c|c|c|c|c|c|c|c|c|c|c|c|}
\hline $\begin{array}{l}\text { a) DJF Jet } \\
\text { driver }\end{array}$ & CET & EW & SEE & SWE & CE & NWE & NEE & S & SS & NS & ES & NI \\
\hline $\begin{array}{l}\text { November } \\
\text { BKI }\end{array}$ & 0.36 & 0.06 & -0.05 & 0.11 & 0.08 & 0.16 & 0 & 0.2 & 0.21 & 0.23 & 0.04 & 0.21 \\
\hline $\begin{array}{l}\text { September } \\
\text { GI }\end{array}$ & 0.15 & 0.14 & 0.21 & 0.15 & 0.1 & 0.07 & -0.01 & 0.06 & 0.09 & 0 & 0.1 & 0.11 \\
\hline $\begin{array}{l}\text { October Eu } \\
\text { snow* }\end{array}$ & -0.17 & 0.25 & 0.35 & 0.21 & 0.32 & -0.03 & 0.22 & 0.19 & 0.17 & -0.32 & 0.11 & 0.04 \\
\hline $\begin{array}{l}\text { September } \\
\text { AMO }\end{array}$ & -0.04 & 0.02 & 0.04 & -0.03 & 0.07 & 0.02 & 0.05 & 0.03 & 0.05 & -0.07 & 0.08 & 0.01 \\
\hline $\begin{array}{l}\text { June SST } \\
\text { tripole }\end{array}$ & 0.12 & 0.1 & 0.04 & 0.14 & 0.06 & 0.11 & 0.06 & 0.13 & 0.08 & 0.15 & 0.14 & 0.13 \\
\hline $\begin{array}{l}\text { October } \\
\text { QBO }\end{array}$ & 0.06 & -0.01 & -0.03 & -0.03 & 0.05 & 0.09 & 0.02 & 0.16 & 0.13 & 0.16 & 0.15 & 0.04 \\
\hline $\begin{array}{l}\text { October } \\
\text { N3.4 }\end{array}$ & -0.16 & 0.13 & 0.22 & 0.11 & 0.2 & -0.12 & 0.1 & 0.23 & 0.23 & -0.26 & 0.09 & 0.14 \\
\hline
\end{tabular}

\begin{tabular}{|l|l|l|l|l|l|l|l|l|l|l|l|l|}
\hline $\begin{array}{l}\text { b) JJA jet } \\
\text { driver }\end{array}$ & CET & EW & SEE & SWE & CE & NWE & NEE & S & SS & NS & ES & NI \\
\hline $\begin{array}{l}\text { November } \\
\text { BKI }\end{array}$ & 0.27 & -0.39 & -0.3 & -0.35 & -0.37 & -0.41 & -0.42 & 0.43 & -0.39 & -0.24 & -0.46 & -0.47 \\
\hline $\begin{array}{l}\text { February } \\
\text { NA snow* }\end{array}$ & -0.21 & 0.25 & 0.15 & 0.23 & 0.26 & 0.23 & 0.31 & 0.27 & 0.25 & 0.17 & 0.32 & 0.26 \\
\hline $\begin{array}{l}\text { January } \\
\text { AMO }\end{array}$ & 0.01 & 0.26 & 0.17 & 0.17 & 0.26 & 0.31 & 0.36 & 0.29 & 0.24 & 0.08 & 0.37 & 0.27 \\
\hline $\begin{array}{l}\text { May SST } \\
\text { tripole }\end{array}$ & -0.05 & -0.03 & 0.01 & -0.07 & 0.04 & -0.06 & -0.06 & 0.19 & -0.16 & -0.25 & -0.14 & -0.05 \\
\hline $\begin{array}{l}\text { June solar } \\
\text { lead 4 }\end{array}$ & 0.14 & -0.26 & -0.32 & -0.25 & -0.17 & -0.25 & -0.21 & 0.23 & -0.24 & -0.05 & -0.27 & -0.21 \\
\hline $\begin{array}{l}\text { January } \\
\text { AR* }\end{array}$ & -0.15 & 0.15 & 0.1 & 0.14 & 0.08 & 0.19 & 0.19 & 0.33 & 0.35 & 0.33 & 0.25 & 0.19 \\
\hline
\end{tabular}

Table 4. Correlations between identified detrended drivers of jet speed and latitude for a) winter (DJF) and b) summer (JJA) with precipitation and temperature (CET) time series for the UK, 1955-2014, except for those marked * where the correlation is from 1980 due to availability of predictor time series. Significant correlations are orange (positive) and blue (negative) with $p \leq 0.05$ (0.01) light (dark). BKI =Barents-Kara sea-ice, GI=Greenland Sea ice, Eu snow=Eurasian snow cover, NA snow=North American snow cover, AMO =Atlantic 
Multidecadal Oscillation, tripole SST =North Atlantic tripole pattern of SST, QBO=QuasiBiennial Oscillation, solar lead 4=solar sunspot cycle leading by four years, AR=tropical Atlantic rainfall. UK regions are as in Figure S1. 


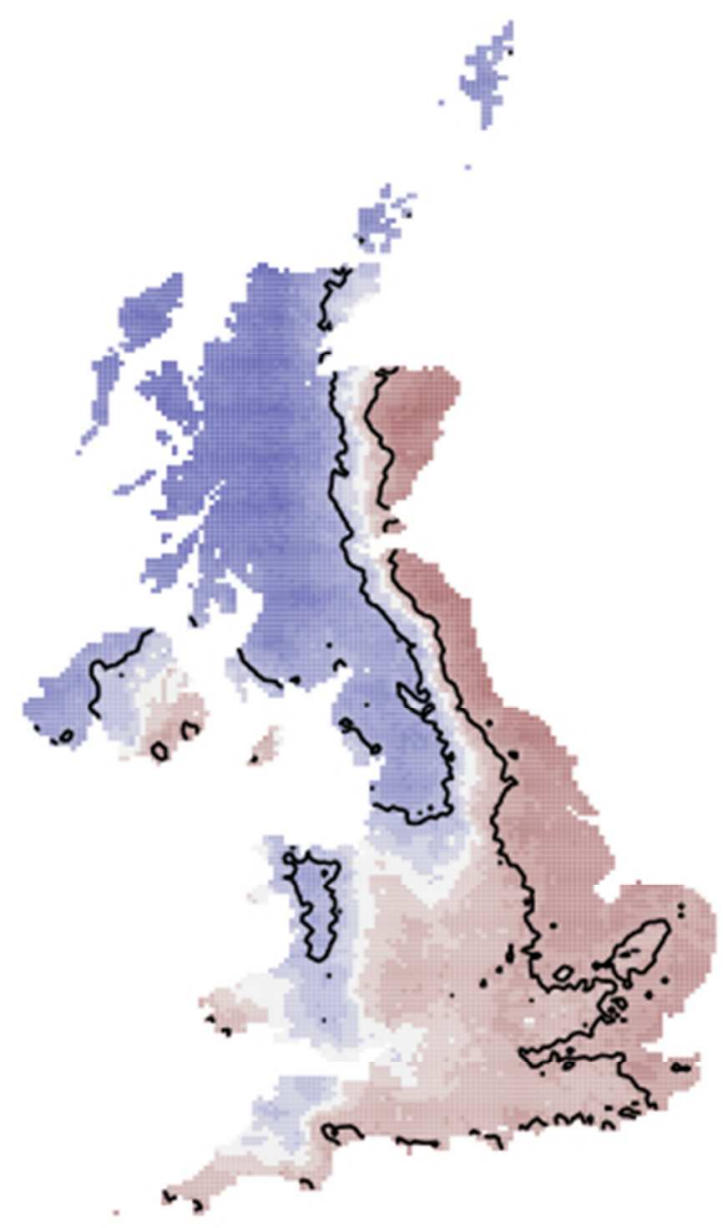

North Atlantic circulation indices: links with summer and winter UK temperature and precipitation and implications for seasonal forecasting.

Richard J. Hall* and Edward Hanna

The winter North Atlantic Oscillation is predictable from a few months ahead, but does not explain all regional UK precipitation and temperature anomalies. We examine associations between a number of circulation indices and UK summer and winter temperature and rainfall patterns. The East Atlantic and Scandinavian patterns explain significant regional variations in UK weather, and some drivers of summer jet stream variability are directly associated with summer temperature and precipitation variability. There is potential to develop improved regional seasonal forecasts. 